\title{
DER KAPERFAHRER JoHANn STORTEBEKER Aus DANZIG
}

\author{
BEOBACHTUNGEN ZUR GESCHICHTE DER „VITALIENBRÜDER“
}

von Gregor Rohmann

1. Zwischen Mythos und Wissenschaft:

Die Vitalienbrüder als Forschungsproblem

Sujets der alltäglichen Geschichtswahrnehmung erfüllen vielfach identitätsstiftende Funktionen, sie dienen als Mythen.' In diesen Fällen treten Wissenschaft und Alltagswahrnehmung in ein komplexes Wechselverhältnis: Einerseits erwartet die Gesellschaft von den Historikern Aufklärung, andererseits hat ein kritischer Impetus gegen die Wirkmacht der Legenden in aller Regel schlicht keine Chance. Dennoch wird im Forschungsbetrieb das Pathos der Rationalität gern bemüht, um den eigenen Explikationen Autorität zu verschaffen. Allerdings erweckt die Beschäftigung mit Themen von populärem Interesse in weiten Kreisen der Fachwissenschaft oft auch den Verdacht mangelnder Seriosität. Der Ruch des Legendären belastet jede fachliche Auseinandersetzung, sodass Wissenschaftler sich etwa mit dem historischen Hintergrund von Sagengestalten entweder gar nicht oder eher abseits ihrer hauptsächlichen Forschungsfelder befassen. Man mag dies auf die traditionelle Scheu des Gelehrten vor dem Publikum zurückführen. Man mag auf die in den Medien gern kolportierten und von der Philologie in aller Regel zu Recht als unhaltbar kritisierten Versuche verweisen, populäre Erzählstoffe (natur-)wissenschaftlich zu erklären. Dies alles jedenfalls führt zu einer Stagnation der Forschung gerade in Bereichen, in denen die alltägliche Mythenproduktion immer neue Blüten treibt. Und die Abneigung der Fachwissenschaft gegenüber einer mehr als anekdotischen Auseinandersetzung verhindert eine konsequente Bereinigung des Forschungsstandes von Versatzstücken der Legende.

\footnotetext{
' Für zahlreiche Anregungen danke ich Volker Verhoff, Tobias Klüter, Michael Zozmann und Christian Fieseler. Mein besonderer Dank gilt Jörgen Bracker, der den Anstoß gab für meine Beschäftigung mit den Vitalienbrüdern und diese in vielen Gesprächen begleitet hat.
} 
Mit großer Prägnanz lassen sich diese Beobachtungen belegen am Beispiel der „Vitalienbrüder“: Klaus Störtebeker und seine Kumpanen füllen allemal die Kassen, sei es als populäres Sachbuch, ${ }^{2}$ als Roman oder Freiluftschauspiel, sei es als TV-Dokumentation oder Fernsehfilm. In aller Regel wird dabei entweder das Faszinosum des brutalen Gewaltmenschen oder das des Sozialrebellen bedient, oft auch beide zugleich. In die Gazetten - freilich wiederum weniger ins seriöse Feuilleton als vielmehr ins "Vermischte" - brachte es etwa der zweifelhafte Versuch, auch diesen Mythos forensisch zu „entschlüsseln“, konkret: der Legendengestalt eine Gesichtsrekonstruktion und schließlich sogar eine DNA-Analyse zu verabfolgen. ${ }^{3}$ Geschichtswissenschaftlich jedoch sind die „Vitalienbrüder" bis heute ein in beinahe jeder Hinsicht unverstandenes Phänomen der spätmittelalterlichen Geschichte.

Wer und was nämlich waren sie? Woher kamen sie? Waren sie organisiert, und wenn: wie? Welche Funktionen erfüllten sie? Wie war Ihre rechtliche und soziale Stellung? Für all diese Fragen stützt sich die Literatur nach wie vor weitgehend auf den Forschungsstand der Wende zum 20. Jahrhundert. ${ }^{4}$ Fruchtbare Impulse gingen seit den Achtziger Jahren von Jörgen Bracker ${ }^{5}$ und Wilfried Ehbrecht ${ }^{6}$ aus. Insgesamt jedoch hat das

${ }^{2}$ Mangels wissenschaftlicher Konkurrenz können diese eine erhebliche Breitenwirkung entfalten, so etwa: Harm BENTS, Störtebeker. Dichtung und Wahrheit, Norden '1990 (2003); Dieter Zimmerling, Störtebeker und Co. Die Blütezeit der Seeräuber in Nord- und Ostsee, Frankfurt am Main '1988.

${ }^{3}$ „Der Kopf des Freibeuters - Das Geheimnis des Störtebeker-Schädels", Spiegel TV 2004/2005, Sendeplatz: VOX; dazu: Klaus Störtebeker. Ein Mythos wird entschlüsselt, hg. von Ralf WiechmanN, Günter BRÄUER, Klaus PüSCHEL, München 2003. Der Verf. war an diesem Unternehmen am Rande beteiligt - eine Erfahrung, auf die auch vorstehende Anmerkungen zurückgehen.

${ }^{4}$ Karl KoppmanN, Der Seeräuber Klaus Störtebeker in Geschichte und Sage, in: HGbll. 1877, S. 37-58; DERS., Die Vitalienbrüder, in: HR I,4, S. V-XXIII; Hans-Christian CORDSEN, Beiträge zur Geschichte der Vitalienbrüder, Halle 1907; vgl. weiterhin: Fritz TEICHMANN, Die Stellung und Politik der hansischen Seestädte gegenüber den Vitalienbrüdern in den nordischen Thronwirren 1389-1400, Diss. phil. Berlin (1928) 1931; Josef WANKE, Die Vitalienbrüder in Oldenburg, 1395-1433, Oldenburg 1910; Hans NIRRNHEIM, Hamburg und Ostfriesland in der ersten Hälfte des 15. Jahrhunderts. Ein Beitrag zur hansisch-friesischen Geschichte, Hamburg 1890; aus jüngerer Zeit: Ute SCHEURLEN, Über Handel und Seeraub im 14. und 15. Jahrhundert an der ostfriesischen Küste, Diss. phil. Hamburg 1974; als Überblick: Matthias PuHLE, Die Vitalienbrüder. Klaus Störtebeker und die Seeräuber der Hansezeit, Frankfurt am Main '1992.

${ }^{5}$ Zusammengefasst in: Jörgen BRACKER, Klaus Störtebeker - Nur einer von ihnen. Die Geschichte der Vitalienbrüder, in: WiECHMANN u. a. (Hg.), Mythos (wie Anm. 3), S. 9-59; vgl. die Beiträge in: Die Hanse. Lebenswirklichkeit und Mythos, Katalog, Hamburg/Rostock 1989/1990 ( $\left.{ }^{2} 1998\right)$, hg. von Jörgen BRACKER; und in: „Gottes Freund - Aller Welt Feind“" Von Seeraub und Konvoifahrt. Störtebeker und die Folgen, hg. von Jörgen BRACKER, Hamburg 2001 .

${ }^{\circ}$ Wilfried EHBRECHT, Hansen, Friesen und Vitalienbrüder an der Wende zum 15. Jahrhundert, in: Niederlande und Nordwestdeutschland. Studien zur Regional- und Stadtge- 
1973 von Friedrich Benninghoven eingeforderte Forschungsprogramm nichts von seiner Aktualität eingebüßt. ${ }^{7}$

Mit Blick auf den Quellenbefund hatte er eine Untersuchungszeit von 1389 bis 1435 eingefordert - ein Postulat, dass von der Forschung unter dem Eindruck der Störtebeker-Erzählung mit ihrem Endpunkt 1400/1401 beinahe regelmäßig ignoriert wird. ${ }^{8}$ Als Untersuchungsraum schlug er ganz Nordeuropa vom Ärmelkanal bis zur Newa-Mündung vor - während sich die Literatur nach wie vor gern mit der westlichen Ostsee und Ostfriesland bescheidet. Für diesen weiten Bereich schwebte ihm eine grundlegende Erfassung auch der ungedruckten Quellen vor - vielleicht der einzige Weg, der präjudizierenden Wirkung der Editions- und Forschungspraxis des späten 19. Jahrhunderts zu entgehen. Den größten Ertrag versprach sich Benninghoven von einer umfassenden Prosopographie - angesichts der großen Zahl überlieferter Beteiligter und des geringen sozialgeschichtlichen Erschließungsgrades auch dies sicher zu Recht. Als Ziel sah er mit Michel Mollat" eine vergleichende Geschichte des spätmittelalterlichen Kaperwesens, insbesondere bezüglich der geographischen und wirtschaftlichen Voraussetzungen, der sozialen Strukturen, der politischen Rahmenbedingungen, der rechtlichen Grundlagen und schließlich des mentalitätsgeschichtlichen Hintergrunds. ${ }^{10}$

Die von Benninghoven benannten Desiderate werden nun auch in den folgenden Ausführungen nicht erfüllt. Umso mehr aber soll auf Ihre Berechtigung hingewiesen werden. Mit Michel Mollat soll die Geschichte der „Vitalienbrüder“ als entscheidender Schritt in der Entwicklung des Kaperrechts und damit im Prozess der Staatsbildung begriffen werden (Kap. 2 und 4). " Zumindest in Umrissen notwendig ist dazu eine Einord-

schichte Nordwestkontinentaleuropas im Mittelalter und in der Neuzeit, hg. von Wilfried EhBrecht, Heinz SCHILling, Köln 1983, S.61-98: DerS., Von Seeräubern, Hansen und Häuptlingen im 15. Jahrhundert. Ein Beitrag zum Verständnis der friesischen Geschichte des Spätmittelalters als Teil und Spiegelbild frühmoderner Staatsbildung im kontinentalen Nordwesteuropa, in: Herrschaft und Verfassungsstrukturen im Nordwesten des Reiches, Franz Petri zum Gedächtnis, hg. von Bernhard SiCKEN, Köln 1993 (Städteforschung. Bd. A 35), S. 47-88: zuletzt der Sammelband: DeRS. (Hg.), Störtebeker. 600 Jahre nach seinem Tod. Seeraub an der südlichen Nordseeküste vom 14. bis zum 16. Jahrhundert (Hansische Studien, Bd. 15), Trier 2005.

${ }^{7}$ Friedrich BENNINGHOVEN, Die Vitalienbrüder als Forschungsproblem, in: Kultur und Politik im Ostseeraum und im Norden 1350-1450. Visby Symposiet för historiska Vetenskaper 197! (Acta Visbyensia IV), Visby 1973, S. 41-52.

${ }^{8}$ Vgl. etwa Puhle, Vitalienbrüder (wie Anm. 4), S. 143-145. Dagegen grundlegend: EHBRECHT, Seeräuber (wie Anm. 6).

${ }_{9}^{9}$ Michel Mollat, Guerre de course et piraterie à la fin du Moyen Age: Aspects économiques et sociaux. Position de problèmes, in: HGbll. 90, 1972, S. 1-14.

${ }^{10}$ Benninghoven, Vitalienbrüder (wie Anm. 7), S. 43-49.

"Mollat, Guerre de course (wie Anm. 9), S. 10-12. 
nung des Phänomens in die politischen Konfliktlinien innerhalb der Hanse, zwischen den Städten und den umliegenden Mächten, wie auch diesen untereinander (Kap. 3). Vor allem jedoch soll die von Benninghoven als Schlüssel zu einem vertieften Verständnis der „Vitalienbrüder" vorgeschlagene prosopographische Erschließung vorgeführt werden am Beispiel der in der Alltagswahrnehmung prominentesten quellenmäßig belegten Figur aus dem Umkreis von Piraterie bzw. Kaperfahrt in der Zeit um 1400 (Kap. 5). Ich möchte also eine neue Hypothese zum historischen Hintergrund und zur Entstehung der Störtebeker-Legende entwickeln (Kap. 6). Und ich möchte damit zumindest andeuten, wie viel Erkenntnisgewinn eine kritische Erforschung der „Vitalienbrüder“ für die Zukunft verspricht. Die Geschichtswissenschaft könnte hier nicht nur im Wettbewerb mit Liebhabern aller Couleur ihre Relevanz beweisen. Sie könnte auch zu einem besseren Verständnis eines der zentralen Probleme der spätmittelalterlichen Kriegs- und Wirtschaftsgeschichte kommen.

Als vitalienses, „Vitalienbrüder“ und ähnliches bezeichnen die Quellen seit 1390 Gruppen von Seeleuten, die sich an verschiedenen Konflikten im Ost- und Nordseeraum beteiligten. ${ }^{12}$ Zurückgeführt wird ihre Existenz in der Regel auf die seit den 1370er Jahren von den Mecklenburgern im Kampf um die schwedische Königskrone gegen Dänemark mobilisierten Truppen. Bereits Albert Krantz vergleicht die Vitalienbrüder 1517 mit den an Land operierenden Söldnerkompanien. ${ }^{13}$ Und schon der Lübecker Chronist Reimar Kock führt Mitte des 16. Jahrhunderts ihren Namen darauf zurück, dass sie sich ihren Lebensunterhalt, ihre „Vitalien“, selbst hätten verdienen müssen. ${ }^{14}$ Hans-Christian Cordsen hat 1907 die Bezeichnung vitalienses überzeugend auf französische Vorbilder im Seekrieg gegen England zurückgeführt. ${ }^{15}$ Die „Vitalienbrüder“ lebten also von der

${ }^{12}$ Vgl. Cordsen, Beiträge (wie Anm. 4), S. 16-20; David K. BJork. Piracy in the Baltic, 1375-1398, in: Speculum 18 (1943), S. 39-68, hier: S. 59f.; PuHLE, Vitalienbrüder (wie Anm. 4), S. 41; EHBRECHT, Hansen (wie Anm. 6), S. 66; BRACKER, Jörgen. Von Seeraub und Kaperfahrt im 14. Jahrhundert, in: DERS. (Hg.), Gottes Freund (wie Anm. 5), S. 6-35, hier: S. 16; Constantin HRUSCHKA, Kriegsführung und Geschichtsschreibung im Spätmittelalter. Eine Untersuchung zur Chronistik der Konzilszeit (Kollektive Einstellungen und sozialer Wandel, N.F., Bd. 5), Köln 2001, S. 167 ff. (über Hermann Korner).

${ }^{13}$ Hier zitiert nach der deutschen Ausgabe: Albert KRANTZ, WANDALIA. oder Beschreibung Wendischer Geschicht, Lübeck 1601, S. 324: [...] das sein Kriegsleute die nicht vmb soldt, sondern nur vmb die Beute auff ir eigen gefahr vnd gewinn außziehen. Vgl. Jörgen BRACKER, Störtebeker - Der Ruhm der Hanseaten, in: DERS. (Hg.), Die Hanse (wie Anm. 5), Bd. 1, S. 661-666, hier: S. 663.

${ }^{14}$ Vgl. Matthias Puhle, Die Vitalienbrüder - Söldner, Seeräuber? In: EHBRECht (Hg.), Störtebeker (wie Anm. 6), S. 15-22, hier: S. 17f.

${ }^{15}$ CORDSEN, Beiträge (wie Anm. 4), S. 24. Dennoch wird auch in wissenschaftlichen Literatur immer noch gern die Herleitung der Bezeichnung aus den angeblich oder tatsächlich ins belagerte Stockholm transportierten „Vitalien“ kolportiert, vgl. etwa: A. ERLER. (Art.) Seeräuberei, in: HRG IV (1990), Sp. 1592-1596, hier: Sp. 1593. 
Beute, die sie machten. Haben wir es demnach - um den Forschungsstand kurz zu resumieren - mit ,rechtmäßige[n] Unternehmer[n] im Handelskrieg auf fürstliche Veranlassung“ zu tun, ${ }^{16}$ mit „Söldner[n] zur See mit der Berechtigung zur Selbstentlohnung “, ${ }^{17}$ die sich von den Mecklenburgern und spätcrhin von anderen Fürsten mit „Kaperbriefen“ ausstatten ließen? ${ }^{18}$ Und waren die Vitalier eine Bruderschaft, eine genossenschaftliche Organisation wie die zeitgenössischen Söldnerkompanien, aber auch wie die Gilden und Fahrergesellschaften der Städte? ${ }^{19}$ Hatte diese Bruderschaft gar einen sozialrevolutionären Impetus, und wurden sie deshalb von der Hanse „kriminalisiert“? ${ }^{20}$ Oder kam es neben der legitimen Kaperfahrt zumindest auch zu räuberischen Übergriffen gegen Dritte? ${ }^{21}$ Waren sie nur bis zum Frieden von Skanör und Falsterbo 1395 legitime Kombattanten, denen dann die Kapererlaubnis entzogen wurde, weshalb sie aus Gründen der Existenzsicherung ihr Handwerk als Seeraub weiter betrieben ${ }^{22}$ Oder handelt es sich schließlich nicht doch schlechterdings um ,nichts als grausame und habgierige Räuber", ${ }^{23}$ waren die Vitalienbrüder also ,ganz gewöhnliche Kriminelle"? ${ }^{24}$ Bezeichnet die Literatur sie also vielfach zu Recht als „Piraten“? ${ }^{25}$ Waren sie als solche ein Phänomen der Krise des späten Mittelalters, rekrutiert aus Leidtragenden der notorischen Kata-

${ }^{16}$ Benninghoven, Vitalienbrüder (wie Anm. 7), S. 47.

${ }^{17}$ Ehbrecht, Hansen (wie Anm. 6), S. 71; vgl. Ders., Seeräuber (wie Anm. 6), S. 48f., S. 65f., S. 71 .

${ }^{18}$ So schon der Lübecker Chronist Reimar Kock Mitte des 16. Jahrhunderts, vgl. PuHLE, Söldner (wie Anm. 14), S. 33f.; vgl. BRACKER, Nur einer von ihnen (wie Anm. 5), S. 13-16; DERS., Seerauh (wie Anm. 12), S. 20; vgl. schon: LiSCH, G. C. F.. Beitrag zur Geschichte der Vitalienbrüder und Landstädte am Ende des 14. Jahrhunderts, in: Jahrbuch des Vereins für Mecklenburgische Geschichte und Altertumskunde 15 (1850), S. 5I-69, hier: S. 54 f.

${ }^{19}$ Ehrrecht, Seeräuber (wie Anm. 6), S. 69f.; PUHLE, Vitalienbrüder (wie Anm. 4), S. 153-155; vor allem aber: BRACKER, Seeraub (wie Anm. 12), S. 13, 17; DERS., Nur einer von ihnen (wie Anm. 5), S. 20-22; vorsichtiger: BENNINGHOVEN, Vitalienbrüder (wie Anm. 7), S. 50-52.

${ }^{20}$ BRACKER, Ruhm (wie Anm. 13), S. 662f.; Ders., Nur einer von ihnen (wie Anm. 5), S. 29f.; vgl. Postel, Rainer, Der Pirat, der Volksheld und der Kopf unter dem Arm, in: WIECHMANN u. a. (Hg.), Mythos (wie Anm. 3), S. 61-77, hier: S. 75.

${ }^{21}$ BENNINGHOVEN, Vitalienbrüder (wie Anm. 7), S. 47; Andreas KAMMLER, Up eventur. Untersuchungen zur Kaperschiffahrt 1471-1512, vornehmlich aus Hamburger und Lübecker Quellen, St. Katharinen 2005, S. 48.

22 So schon CORDSEN, Beiträge (wie Anm. 4), S. 16; PUHLE, Vitalienbrüder (wie Anm. 4), S. 85f.; Karin CiESLIK, Der Mythos vom Außenseiter. Klaus Störtebeker, Pirat und Volksheld des Nordens, in: Herrscher, Helden, Heilige. hg. von Ulrich MULLER. Werner WUNDERLICH (Mittelalter-Mythen, Bd. 1), St. Gallen 1996, S. 451-466, hier: S. 453.

${ }^{23}$ So Erich Hoffmann 1997, zitiert nach: POSTEl, Pirat (wie Anm. 20), S. 63.

${ }^{24}$ Jann M. WITT, Ein ganz gewöhnlicher Krimineller, in: Damals. Das Magazin für Geschichte und Kultur 4 (2006), S. 19.

${ }^{25}$ So etwa: BJoRk, Piracy (wie Anm. 12); ERLER, (Art.) Seeräuberei (wie Anm. 15), Sp. 1593. 
strophen, Epidemien, Glaubenskämpfe und sozialen Verwerfungen ihrer Zeit? $?^{26}$

\author{
2. „Seeräuber" und „Auslieger“: \\ Kriegsführung und Kaperrecht im späten Mittelalter
}

Die Diskussion dieser Fragen ist maßgeblich geprägt durch ein für Nordeuropa um 1400 anachronistisches Verständnis des See- und Fehderechts. Geht sie doch von einer klaren Unterscheidung zwischen kriminellem Raub und legitimer Entnahme von Konterbanden aus, wie sie erst im Kaperrecht des 16. und 17. Jahrhunderts juristisch ausformuliert wurde: $:^{27}$ Nicht nur feindliche Schiffe und Ladungen wurden demnach in der frühen Neuzeit als legitime Angriffsziele gesehen, sondern auch neutrale Schiffe mit feindlicher oder für den Feind bestimmter Ladung oder neutrale Ladungen auf feindlichen Schiffen, de facto also jeder Transport kriegswichtiger Güter zu oder von einer kriegführenden Macht. ${ }^{28}$ Durchgeführt wurden diese Prisen durch beauftragte Gewaltprofessionelle. Da die frühneuzeitlichen Mächte keine stehende Marine unterhielten, beschränkte sich die Seekriegführung weitestgehend auf diese privatwirtschaftliche Form. Die genau geregelte Aufteilung der Beute (nach vorheriger prisenrechtlicher Überprüfung) ersetzte zum Teil oder vollständig die Bezahlung - ein für den Auftraggeber attraktives Modell, das freilich fast zwangsläufig konfliktverschärfend wirkte. Notwendige Voraussetzung für die legitime Prisennahme war eine ausdrückliche, schriftliche Ankündigung des Kaperkriegs gegenüber dem Feind und den neutralen Mächten und ebenso eine schriftliche, formal präzise normierte Bestätigung des Kaperrechts gegenüber dem Ausführenden. ${ }^{29}$ Es liegt freilich auf der Hand, dass diese

${ }^{26}$ PUHLE, Söldner (wie Anm. 14), S. 19; Zur angeblichen Krise des späten Mittelalters vgl. Peter SCHUSTER, Die Krise des Spätmittelalters. Zur Evidenz eines sozial- und wirtschaftsgeschichtlichen Paradigmas in der Geschichtsschreibung des 20. Jahrhunderts, in: HZ 269 (1999), S. 19-55.

${ }^{27}$ Darauf weist zurecht hin: PuHLE, Vitalienbrüder (wie Anm. 4), S. 31 f., der freilich, S. 86f., daraus unrichtig schließt, die Frage der Rechtmäßigkeit sei letztlich unerheblich gewesen.

${ }^{28}$ BENNINGHOVEN, Vitalienbrüder (wie Anm. 7), S. 47f.

${ }^{29}$ Mollat, Guerre de course (wie Anm. 9), S. 1; Kammler, up eventur (wie Anm. 21). S. 32-36; Ulrich ANDERMANN, Spätmittelalterlicher Seeraub als Kriminaldelikt und seine Bestrafung, in: EhBRECHT (Hg.), Störtebeker (wie Anm. 6), S. 23-37: Karl-Heinz BöHRINGER, Das Recht der Prise gegen Neutrale in der Praxis des späten Mittelalters. Diss. jur. Frankfurt am Main 1970 (Das geltende Seerecht in Einzeldarstellungen, Bd. 7), Frankfurt am Main 1972, S. I ff.; DeRS., (Art.) Kaperei, in: HRG II (1978), Sp. 620-623; KULSRUD, Carl J., Maritime Neutrality to 1780. A History of the Main Principles Governing Neutrality and Bellingerency to 1780, Boston 1936; Max WIEGNER. Die Kriegskonterbande in der Völkerrechtspraxis und der Staatenwissenschaft, Berlin 1904; nicht zugänglich war mir: Hermann HARTMEYER, Zum Recht der Kriegscontrebande, Diss. jur. Berlin 1903. 
formaljuristische Regulierung in der Praxis des Handelskrieges Konflikte ebenfalls weniger löste als vielmehr generierte. ${ }^{30}$

Kriegsrecht und Seerecht in diesem Sinne jedoch waren Produkte und zugleich maßgebliche Medien der Formierung der neuzeitlichen Staatlichkeit in Europa. Michel Mollat hat schon 1972 nachdrücklich darauf hingewiesen, dass neben den Auseinandersetzungen des Hundertjährigen Krieges gerade die Konflikte im Einzugsgebiet der Hanse an der Wende zum 15. Jahrhundert eine entscheidende Wegmarke dieses Prozesses darstellen. ${ }^{31}$

Am Beispiel Hamburgs und Lübecks hat Andreas Kammler nachgezeichnet, wie in der zweiten Hälfte des 15. Jahrhunderts schriftliche Regulierung und vertragliche Verbindlichkeit in die Praxis der hansestädtischen Seekriegsführung eindrangen. ${ }^{32}$ Denn wie die Städte zu Lande auf eine Delegitimierung der adeligen Fehdeführung, des ruten[s] und roven $[s],{ }^{33}$ hinarbeiteten, so war ihnen auch auf See an der Freiheit des Handels gelegen. Allerdings: Wie an Land selbstverständlich nie die eigenen, sondern immer nur die Fehden der anderen illegitim waren, ${ }^{34}$ so betrieben auch auf See die gleichen Städte auch selbst die Kriegführung vermittels der sogenannten „Auslieger", die vielfach privatwirtschaftlich geführt und mit Söldnertruppen besetzt waren. ${ }^{35}$ Wie an Land waren Fehdeführer und Fehdehelfer also als Kombattanten legitimiert. Das hieß jedoch nicht, dass sich daraus für sie ein unzweifelhafter Schutzanspruch etwa auf schonende Behandlung abgeleitet hätte. Gefangene wurden daher von der Gegenseite schlicht als Räuber bzw. Seeräuber behandelt, wenn dem nicht politische oder taktische Erwägungen entgegen standen. ${ }^{36}$ Vielmehr zielte die beginnende Regulierung des Kaperrechts vor allem auf einen Schutz neutraler Dritter vor Übergriffen. ${ }^{37}$ Schadensersatzforderun-

\footnotetext{
${ }^{30}$ Robert BoHN, Die Piraten, München 2003, S. 13-16.

${ }^{31}$ MOLlat, Guerre de course (wie Anm. 9), S. 2, S. 10-13.

${ }^{32}$ KAMMLER, up eventur (wie Anm. 21); ebenso - rechtsgeschichtlich präziser - schon: BÖHRINGER, Prise (wie Anm. 29).

${ }^{33}$ Wilfried EHBRECHT, Ruten, roven, dat is gheyn schande, Dat doynt de besten van dem lande. Bemerkungen zu adligem Land- und Seeraub im spätmittelalterlichen Nordwesten, in: DERS. (Hg.), Störtebeker (wie Anm. 6), S. 253-273, hier: S. 269f.; Ulrich ANDERMANN, Ritterliche Gewalt und bürgerliche Selbstbehauptung. Untersuchungen zur Kriminalisierung und Bekämpfung des spätmittelalterlichen Raubrittertums am Beispiel norddeutscher Hansestädte, Frankfurt am Main u. a. 1991, S. 39-46.

${ }^{34}$ BÖHringer, Prise (wie Anm. 29), S. 2 f.

${ }^{35}$ KAMMLER, up eventur (wie Anm. 21), S. 3, S. 31 f.

${ }^{36}$ KAMMLER, up eventur (wie Anm. 21), S. 98-100; zur ritterlichen Fehde an Land und ihrer Behandlung durch die Städte vgl.: ANDERMANN: Ritterliche Gewalt (wie Anm. 33), S. $251 \mathrm{f}$.

${ }^{37}$ KAMMLER, up eventur (wie Anm. 21), S. 38-40; Kammlers Argumentation ist leider nicht frei von Widersprüchen und Kurzschlüssen. So schreibt er, S. 2 f., dass es im späten
} 
gen wurden daher in der Regel eher zuvorkommend behandelt, wollte man doch die wirtschaftlichen und diplomatischen Verbindungen zu neutralen Mächten (und ebenso zu vormaligen Gegnern) nicht belasten. ${ }^{38}$ Folglich sind auch aus der zweiten Hälfte des 15. Jahrhunderts im Hanseraum keine schriftlichen Kapererlaubnisse zur Mitführung an Bord von "Ausliegern“ überliefert. Die bekannten „Ausliegerbriefe“ waren keine „Kaperbriefe“ im späteren Sinne, sondern dienten allein der vertraglichen Vereinbarung zwischen Auftraggeber und Kriegsunternehmer. ${ }^{39}$

Überhaupt gab es um 1400 offenbar verschiedene rechtliche Formen der legitimen Seekriegsführung: Die Städte und Herren rüsteten im konkreten Bedarfsfall vereinzelt auf eigene Kosten vredekoggen bzw. shepe van orloghen aus, mit Söldnern besetzte und von Ratsherren bzw. Höflingen befehligte Kriegsschiffe. Häufiger waren die in der Hoffnung auf Beute von den Obrigkeiten gemeinsam mit Bürgern bzw. Untertanen finanzierten „Auslieger“. Daneben konnten privatwirtschaftliche Kriegsunternehmer mit der Ausliegerfahrt beauftragt werden, die dann auf eigene Kosten Kämpfer und Seeleute anwarben. Es existierte offenbar ein erhebliches Rekrutierungsreservoir aus gewerbsmäßigen Kämpfern, der sogenannten losen parthey. ${ }^{40}$ Da auch die Handelsschiffe sich mit Bewaffneten schützten, waren die Grenzen diesbezüglich freilich fließend.

Neben den hoheitlichen Ausliegerbriefen existierte zudem noch eine privatrechtliche Form der legitimen Besitzwegnahme: Um einen Rechtsanspruch gegen den Bürger einer fremden Stadt, bzw. Untertan eines fremden Fürsten durchzusetzen, konnte man sich von seiner eigenen Obrigkeit einen „Markebrief" (letter of marque) ausstellen lassen. Durch Arrestierung von Gütern des Kontrahenten oder von Gütern eines seiner Mitbürger konnte ein Kläger die Rechtssprechung in seinem Fall erzwin-

Mittelalter eine Unterscheidung illegitimer und legitimer Aufbringung von Schiffen nicht gegeben habe, verweist, S. 38, jedoch zum Verständnis des entstehenden Prisenrechts auf das spätmittelalterliche Fehderecht. S. 32, Anm. 111, meint er, dass die Unterscheidung von feindlichem und neutralem Gut, Schiff oder Fahrtziel vor der kaperrechtlichen Normierung letztlich gegenstandslos gewesen sei, um dann, S. 34f., auf zahlreiche Konflikte unter Rekurs auf diese Unterscheidung zu verweisen. Dass in der zweiten Hälfte des 15. Jahrhunderts alle Besatzungen gegnerischer Schiffe unterschiedslos als seerovere o. ä. bezeichnet wurden, S. 49, heißt nicht unbedingt, dass man sie auch als Piraten im kriminellen Sinne gesehen hätte, folgt man seiner eigenen These von der sukzessiven Verschiebung der seerechtlichen Normen. Denn in deren Verlauf musste doch auch der alte Terminus ,rover" erst seine neue, eindeutig kriminelle Bedeutung erhalten, vgl. BöHrINGER. Prise (wie Anm. 29), S. 14f.; allg.: EHBRECHT, Ruten (wie Anm. 23); zur präjudizierenden Wirkung des Begriffs „Raubritter" in der Forschung vgl. auch: ANDERMANN: Ritterliche Gewalt (wie Anm. 33), S. 46-56.

${ }^{38}$ KAMMLER, up eventur (wie Anm. 21), S. 56.

${ }^{39}$ KAMmLer, up eventur (wie Anm. 21), S. 32f., S. 35f., S. 99; BöHringer. Prise (wie Anm. 29), S. 42-44.

${ }^{40}$ BöHringer, Prise (wie Anm. 29). S. 39-42, S. 68. 
gen und vor allem einen Wechsel des Gerichtsstandes von der Schuldnerseite in seine Heimat erreichen. Es war dies ein privatrechtlicher, von der Obrigkeit lediglich genehmigter Vollstreckungsakt. Daher liegt auf der Hand, dass durch diese „Markebriefe“ das Konfliktpotential auf See potenziert wurde. Zudem beauftragte man mit der Ausführung der Arresticrung vielfach die professionellen „Auslieger", die so auch zu Friedenszeiten eine legitime Geschäftsgrundlage bekamen. ${ }^{41}$ Zudem konnte jeder fehdeberechtigte Mann auch eigene Rechtsstreitigkeiten und Ehrenhändel austragen - und dabei war es sicherlich nicht ungeschickt, sich auf hoheitlichen Auftrag oder privatrechtliche Vereinbarungen zu stützen.

Schon für die Zeitgenossen war die fehderechtliche Grundlage einer Operation dann nur noch schwer zu durchschauen. Der Vorwurf willkürlicher Gewalt war daher allgegenwärtig. ${ }^{42}$ Dennoch bleibt festzuhalten, dass etwa mit dem Frieden von Skanör und Falsterbo 1395 die Rechtsstellung der "Vitalienbrüder" in mecklenburgischen Diensten nicht grundsätzlich eine andere wurde: Sie wurden nicht zu „Piraten“, sondern blieben, was sie gewesen waren: bezahlte Kämpfer und Eintreiber, denen es nicht schwer gefallen sein dürfte, Aufträge und damit eine ausreichende Legitimation für ihr Geschäft zu finden.

Der Kampf zur See war bis weit in Neuzeit in aller Regel ein direkter Kampf Mann gegen Mann. Als Distanzwaffen kamen im frühen 15. Jahrhundert Bogen, Armbrust und vereinzelt Feuerwaffen zum Einsatz. Sie konnten jedoch nur durch Schädigung der gegnerischen Besatzung das Entern vorbereiten. Die Entscheidung musste in der direkten Auseinandersetzung fallen. Die Besatzungen der Kaperschiffe werden daher aus ausgebildeten und gewaltbereiten Kämpfern und Seeleuten bestanden haben, nicht aber, wie vielfach kolportiert, aus Unterprivilegierten aller Art. ${ }^{43}$ Jeder Kampf bedeutete auch für den Überlegenen eine ganz erhebliche Gefährdung seiner Gesundheit, für den Kriegsunternehmer also eine Belastung seiner Ressourcen. Schon aus ökonomischem Kalkül also mussten Kaperfahrer ihre Gewaltbereitschaft möglichst oft nachhaltig repräsentieren, zugleich jedoch so selten wie möglich zur Anwendung bringen. ${ }^{44}$ Der Alltag der Kaperfahrt dürfte also eher durch latente Gewaltandrohung als durch ihre Anwendung geprägt gewesen sein.

41 Zum Vorhergehenden: BöHringer, Prise (wie Anm. 29), S. 44-51.

${ }^{42}$ Böhringer. Prise (wie Anm. 29), S. 50-52.

${ }^{4.3}$ KAMMLER, up eventur (wie Anm. 21), S. 185-187. 191f.; zur Rekrutierung der „Vitalienbrüder"vgl.: BRACKER, Nur einer von ihnen (wie Anm. 5), S. 9-11, 57-59; BENNINGHOVEN, Vitalienbrüder (wie Anm. 7), S. 48f.; EHBRECHT, Hansen (wie Anm. 6), S. 67f.

${ }^{\text {th }}$ Dies gegen KaMmLER, up eventur (wie Anm. 21), S. $191 \mathrm{f}$. 
Hatte ein „Auslieger“" ein Handelsschiff gesichtet und erreicht, so wurde Kontakt aufgenommen. Der Kaperfahrer hatte sich namentlich zu erkennen zu geben, das Handelsschiff seinen Status im jeweiligen Konflikt, den Status seiner Ladung und seines Zielortes zu klären. Dazu wurden anhand der Frachtpapiere oder durch Beschau an Bord Untersuchungen durchgeführt - freilich angesichts der Ladeverhältnisse nur mit begrenzter Aussicht auf gesicherte Ergebnisse. ${ }^{45}$ Es konnte dann zu Verhandlungen über die Entnahme von Ladung, über die Übernahme des Schiffes oder über die Stellung von Geiseln durch den Kauffahrer kommen. Wenn dieses Verfahren scheiterte, wenn der Kauffahrer Anstalten zur Gegenwehr oder Täuschung machte, konnte und musste der „Auslieger" seine Gewaltandrohung symbolisch, exemplarisch oder im offenen Kampf wahr machen. ${ }^{46} \mathrm{Zu}$ beachten war dabei immer, dass erstens Schiff und Ladung nicht gefährdet werden durften, zweitens gefangene Gegner für potentielle Lösegeldverhandlungen erschlagenen vorzuziehen waren. ${ }^{47}$ Auch in den Prisenordnungen des späteren 15. Jahrhunderts war dieses Verfahren allerdings noch nicht schriftlich normiert. ${ }^{48}$

Dass es freilich gewohnheitsrechtliche Normen der Kaperei bereits um 1400 gegeben hat, legen die jahrelangen Schadensersatzverhandlungen zwischen dem englischen Hof und den Hansestädten bis 1407 nahe: So dokumentieren die für diese Verhandlungen angelegten Schadensverzeichnisse regelmäßig Namen und Herkunft der beteiligten Kaperfahrer, die sich also zu erkennen gegeben hatten. Beschrieben wird dann nicht etwa ein allgemeines Kampfgetümmel. Vielmehr dokumentieren die Geschädigten minutiös die ungerechtfertigte Entnahme bestimmter Güter bzw. die ungerechtfertigte Übernahme des ganzen Schiffes, etwaige ungerechtfertigte Gewaltanwendung gegen Besatzung und Schiff bzw. die unangemessene Behandlung von Geiseln. ${ }^{49}$ Die Geschädigten wussten auch genau, in welche Häfen ihre Schiffe gegebenenfalls verbracht worden waren

\footnotetext{
${ }^{45}$ Für das späte 14. Jahrhundert: BöHRINGER, Prise (wie Anm. 29), S. 34-39.

${ }^{46}$ KAMMLER, up eventur (wie Anm. 21), S. 183-185.

${ }^{47}$ KAMMLER, up eventur (wie Anm. 21), S. 188-191.

${ }^{48}$ KAMMLER, up eventur (wie Anm. 21), S. 183.

${ }^{49}$ Richard HAKLUYT, The Principal Navigations, Voyages, Traffiques and Discoveries of the English Nation, New York $1969\left({ }^{1} 1589\right)$, Bd. II, S. 55-71, z. B. S. 64: Item, in the veere of our Lord 1395. Godekin Mighel, Clays Scheld, Stertebeker, and others their accomplices of the Hans, unlawfully tooke upon the sea a certaine ship of one William Bets of Cley called the Margaret (wherein Robert Robines was master) and conveyed the ship it self unto Mawstrond in Norway, and there robbed the master and his partners of divers commodities, namely of artillerie, furniture, and salt fishes, to the value of 400 . nobles, and one of the said masters mates they maliciously drowned. Vgl. dazu BRACKER, Nur einer von ihnen (wie Anm. 5), S. 46-50.
} 
- weil es sich nicht um offenen Raub, sondern zumindest formell um Arrestierungen handelte. ${ }^{50}$

Der ihnen eigenen Logik nach überliefern diese „Klageakten“ also nicht den Alltag des Kaperwesens, sondern all die Fälle, in denen die Geschädigten eine Möglichkeit sahen, einen Erstattungsanspruch zu crlangen. Freilich sind sie noch nicht Zeugnisse eines elaborierten Kaperrechts. Sie dokumentieren vielmehr den Übergang vom fehdetypischen und erlaubten „Schadentrachten“ gegen den Feind und seine Helfer zur regulierten Prisennahme. Nach Böhringer galt im Zuge einer rechtmäßigen Fehde in Nordeuropa grundsätzlich jedes Schiff, das entweder dem Feind gehörte, irgendwelches feindliches Gut transportierte oder einen feindlichen Zielhafen hatte, als legitimes Ziel. ${ }^{51}$ Das Prinzip der ,infection hostile“ führte dazu, dass - anders als im mediterranen Raum - jedes noch so kleine Frachtstück für den Gegner ein Schiff in seiner Gesamtheit der Neutralität beraubte. ${ }^{52}$ Die Schadensverzeichnisse der englisch-hansischen Verhandlungen legen allerdings den Eindruck nahe, dass von Fall zu Fall durchaus Konterbande von neutralem Gut unterschieden wurden. ${ }^{53}$

Vor dem letzten Drittel des 15. Jahrhunderts scheint es im Nord- und Ostseeraum überhaupt keine schriftliche Normierung der Ausliegerfahrt gegeben zu haben, anders als etwa im englischen und holländisch-flandrischen Raum, wo schon um 1400 zahlreiche Dienstverträge zwischen Fürsten und Kaperfahrern überliefert sind. ${ }^{54}$ Dass mecklenburgische „Kaperbriefe“ für die Vitalienbrüder nicht bekannt sind, liegt demnach vermutlich daran, dass dergleichen im Ostseeraum offenbar noch nicht üblich war. Dies heißt aber nicht, dass man nicht schon zwischen Raub und Fehdeführung unterschieden hätte, dass die Unterscheidung legitimer und illegitimer Gewaltanwendung bzw. legitimer und illegitimer Güterentnahme vor der zweiten Hälfte des 15. Jahrhunderts nicht bekannt gewesen wäre. ${ }^{55}$ Vielmehr gab es ganz offensichtlich einen ungeschrie-

\footnotetext{
${ }^{50}$ Hakluyt, Principal Navigations (wie Anm. 49), Bd. II, S. 55-71.

${ }^{51}$ BöHringer, Prise (wie Anm. 29), S. 8-10.

52 BÖHringer. Prise (wie Anm. 29), S. 10-13.

${ }^{53}$ HaKLUYT, Principal Navigations (wie Anm. 49), Bd. II, S. 62: Item in the yeere of our Lord 1398. about the moneth of September, one Godekin Wisle [...] wickedly and unjustly took out of a ship of Prussia [...].

${ }^{54} \mathrm{Vgl}$. nur die zahlreichen Beispiele bei: KUNZE, Karl (Hg.), Hanseakten aus England, 1275-1412 (Hansische Geschichtsquellen, Bd. 6), Halle 1891, passim; Dieter SEIFERT, Kompagnons und Konkurrenten. Holland und die Hanse im späten Mittelalter (QDhG, NF. 43), Köln 1997, passim; vgl. außerdem: Jan Folkert BAKKER, Groningen, Zeeroof en Kaapvaart, in: EHBRECHT (Hg.), Störtebeker (wie Anm. 6), S. $63 \mathrm{f}$.

${ }^{55}$ Dies gegen PuHLE, Vitalienbrüder (wie Anm. 4), S. 86f. und KAMMLER, up eventur (wie Anm. 21), S. 32. Ein deutliches - leider nurmehr als Regest greifbares - Zeugnis für diese Unterscheidung ist das Schreiben des ostfriesischen Häuptlings Edo Wiemken an die Stadt
} 
benen Kodex von zumindest impliziten Rechtsvorstellungen, die sich aus der beginnenden Rezeption des mediterranen Seerechts oder aus gewohnheitsrechtlichen Konventionen speisten. ${ }^{56}$ So verwendeten die Städte Rostock und Wismar 1391 für ihren „Warschau“, die Ankündigung ihrer Fehdehandlungen gegen Dänemark gegenüber den preußischen Hansestädten, Formulierungen, die denen in späteren dänischen und holländischen Kapervereinbarungen ähneln. Es handelte sich dabei aber noch um ein neues Verfahren, dessen Akzeptanz gerade in diesem Fall umstritten blieb..$^{57}$

Ein grundsätzliches Problem der spätmittelalterlichen Rechtsgeschichte verschärfte die Dynamik der Verhältnisse: Schriftliche Verträge beanspruchten zwar theoretisch Gültigkeit. In der Praxis galten sie jedoch in aller Regel weniger als Konfliktabschluss, sondern als Etappe bei der Durchsetzung der je eigenen politischen Ansprüche. ${ }^{58}$ Sie wurden daher als taktisches Mittel geschlossen und spätestens bei einer Änderung der Rahmenbedingungen früher oder später gebrochen. Dass etwa das Haus Mecklenburg 1395 die Niederlage gegenüber Dänemark eingestehen und Frieden schließen musste, hieß nicht, dass es den Konflikt anschließend nicht weiter betrieben hätte! $!^{59}$ In dieser Situation war die Fortführung des

Hamburg, in dem er sich für die 1401 gefangenen „Vitalienbrüder“ einsetzt: Er nennt sie namentlich und bittet unter Hinweis auf ihren Kombattantenstatus um gute Behandlung, vgl. HR I.5, 44; J. C. M. LAURENT, Klaus Störtebeker, in: ZHGV 2 ( 1847), S. 43-99, hier: S. 98; derartige Gnadengesuche für gefangene Fehdeführende waren an Land offenbar ein häufiges Phänomen, vgl. ANDERMAnN: Ritterliche Fehde (wie Anm. 33), S. 27l f., $307 \mathrm{ff}$.

${ }^{56}$ KAMMLER, up eventur (wie Anm. 21), S. 35.

${ }^{57}$ Böhringer. Prise (wic Anm. 29), S. 13f., S. 64f.; zu Begriff und Rechtsinstitut des „Warschau“ allg. vgl. BÖHRINGER, Prise (wie Anm. 29), S. 18-34, S. 64-66. Zum Fall 1391 vgl. hingegen: BJork. Piracy (wie Anm. 12), S. 58, Anm. 2; CORDSEn, Beiträge (wie Anm. 4), S. 13-16; diesem folgend EнвRеснт: Hansen (wie Anm. 6), S. 64. Anm. 14. der von der Existenz mecklenburgischer Kaperbriefe ausgeht: EHBRECHT, Wilfried, Störtebeker - 600 Jahre nach seinem Tod. Einführung, in: DERS., Störtebeker (wie Anm. 6), S. 1-14, hier: S. 3, vermutet, die Kaperbriefe der Vitalienbrüder seien nicht erhalten, da sie an Bord der Schiffe mitgeführt worden seien, was eine geringe Überlieferungswahrscheinlichkeit in hansestädtischen Archiven zur Folge habe. Freilich wären bei einer schriftlichen Vereinbarung doch Zweitausfertigungen oder andere Gegenüberlieferungen bei den Auftraggebern zu erwarten, vgl. BöHringer. Prise (wie Anm. 29), S. 42-44.

${ }^{58}$ Dass zumal auf politischer Ebene eine Änderung der Machtverhältnisse mit gewissen Verzögerungen eine Neuaushandlung vertraglicher Bindungen zur Folge haben wird, gilt wohl auch heute noch. Unter vormodernen Rechtsbedingungen dürfte dies umso mehr zutreffen, sind diese doch gekennzeichnet durch das Nebeneinander nicht nur konkurrierender Rechtsansprüche, sondern auch konkurrierender Rechtsstrukturen und Rechtsverfahren; vgl. dazu: Dietmar WILlowEIT, Deutsche Verfassungsgeschichte. Vom Frankenreich bis zur Wiedervereinigung Deutschlands, München ${ }^{5} 2005$, S. $3 \mathrm{f}$.

${ }^{59}$ Vgl.: Mats MOGREN, Die Vitalienbrüder und der Burgenbau im nördlichen Ostseeraum, in: BRACKER (Hg.), Hanse (wie Anm. 5), S. 627-633; KoPPMANN, Vitalienbrüder (wie Anm. 4), S. XVII-XXII. 
Handelskrieges durch die mecklenburgischen Kaperfahrer zwar fehderechtlich nicht mehr eindeutig gedeckt. Damit hatte der Gegner ein Argument für Verhandlungen. Dies wurde aber erst dann zum Problem, wenn der politische und militärische Erfolg ausblieb. Alle Konfliktparteien bewegten sich also in einem weiten Spielraum, in dem das sich formierende Prisenrecht einer von vielen mobilisierbaren Faktoren war.

Tendenziell autonom operierende Kaperfahrer konnte man dabei mehr oder weniger klandestin unterstützen, ohne seinen diplomatischen Kredit vollständig zu verspielen - eine Entlastungsfunktion, die den Hansestädten mit ihren eigenen „Ausliegern" weniger offen stand. So leugneten die Mecklenburger nach der Niederlage auf Gotland 1398 die Verantwortung für die Operationen ihrer eigenen Truppen - weshalb die Insel unter ihrer Herrschaft in den Jahren zuvor bis heute gern als „Piratennest" dargestellt wird. ${ }^{60}$ Die Unterscheidung zwischen Seeraub und Prisennahme war also grundsätzlich durchaus schon den Zeitgenossen bewusst. Sie war aber noch nicht normativ fixiert, weshalb politische Spielräume bestanden, welche die Akteure gern nutzten. Will man diese politische Praxis verstehen, darf man jedenfalls nicht die normativen Maßstäbe des 16. oder 17. Jahrhunderts anlegen. ${ }^{61}$

In den Konflikten zwischen den konkurrierenden Mächten Nordeuropas hatte sich ein reiches Betätigungsfeld für Gewaltprofessionelle gebildet, die teils mit Duldung oder im Auftrag wechselnder Herren, teils für ihren Lehnsherren oder ihren Herkunftsort Kaperfahrt betrieben, teils mit privatem Auftrag oder gar in eigener Sache. Sie bewegten sich dabei, auch wenn sie für unterschiedliche Herren fuhren und sich unterschiedlich rekrutierten, rechtlich, aber auch räumlich und organisatorisch unter gemeinsamen Rahmenbedingungen. Und ganz offensichtlich gab es unter ihnen eine erhebliche Fluktuation, was die Tätigkeit, die Auftraggeber und die soziale Stellung anging. Professionelle Söldner, Kaperunternehmer etwa aus dem flandrisch-holländischen Raum, ritterliche Gefolgsleute kriegführender Herren, lokale Adelige der Küstenregionen, hansestädtische Kaufleute und Würdenträger als Kommandeure von Ausliegerschiffen - sie alle betrieben in wechselnden Koalitionen ihr Geschäft.

Schon als die wendischen Städte 1385 den Stralsunder Wulf Wulflam mit der Bekämpfung der „Seeräuber“ beauftragten, enthielt sein Vertrag die vielsagende Klausel: $O k$ schall he nemende to sik nehmen van den

${ }^{60}$ Zur Eroberung Gotlands durch die Vitalienbrüder bzw. mecklenburgischen Truppen vgl. PUHLE, Vitalienbrüder (wie Anm. 4), S. 90-102; BRACKER, Nur einer von Ihnen (wie Anm. 5), S. 24-32.

${ }^{61}$ In diesem Sinne soll daher auch hier von „Kaperung“ und „Kaperfahrt“ bzw. „Seeraub“ gesprochen werden. 
seerovern by sinen wetende, it ensy mit volbort der stede, sunder argelist. ${ }^{62}$ Die „Seeräuber“ sind hier offenbar ein großes Reservoir von Kriegern auf der Suche nach Aufträgen. Die Städte verbieten dem privatwirtschaftlich arbeitenden Kriegsunternehmer Wulflam noch nicht einmal, seine Truppen aus diesem Reservoir zu rekrutieren. Sie beanspruchen aber ein Mitspracherecht - vielleicht, um sicher zu stellen, dass das Unternehmen wirksam zu einer Verringerung des Gefahrenpotentials beiträgt.

Man denke auch an Gerrit Jakobszon aus Enkhuizen, der sich 1401 auf Seiten der Hamburger im Kampf gegen Gödecke Michels verdient machte, noch ein Jahr zuvor aber vom Grafen von Holland gegen die Elbestadt in Dienst genommen worden war. ${ }^{63}$ Sein Landsmann Simon von Utrecht war bekanntlich als Kaperunternehmer nach Hamburg gekommen - und sollte es hier als Held der Kämpfe gegen die „Vitalienbrüder" bis zum Bürgermeister bringen. ${ }^{64}$ Der Danziger Eggherd Schoeff, 1398 Opfer und Nachrichtenüberbringer der ,Vitalienbrüder“" ${ }^{65}$ wurde später selbst als Angreifer gegen englische Schiffe gerichtsnotorisch. ${ }^{66}$

Der Däne Sven Sture kämpfte ab 1395 mit seinen Truppen zunächst gegen die Eroberer Gotlands, wechselte aber 1397 die Seiten und wurde zum Oberbefehlshaber der mecklenburgischen Truppen. ${ }^{67}$ Nach deren Vertreibung durch den Deutschen Orden zog er sich wie viele „Vitalienbrüder", etwa Otto Peccatel und Arndt Stuke, in den Bottnischen Meerbusen zurück. Gemeinsam wechselten die ehemaligen Gegner nun erneut die Seite, um sich 1403/04 an einer dänischen Invasion Gotlands gegen den Deutschen Orden zu beteiligen. ${ }^{68}$ Arndt Stuke stammte aus mecklenburgischem Niederadel und war seit 1380 im Seekrieg seines Herzogshauses gegen die Dänen aktiv gewesen. ${ }^{69}$ Seinesgleichen wird in der Forschung gern als Beispiel für einen ritterlichen „Vitalienbruder“ der frühen Zeit angeführt, die sich nach 1395 gesetzestreu aus dem Kapergeschäft zurückgezogen hätten. ${ }^{70}$ Arndt Stuke jedoch hatte lediglich im richtigen Moment

${ }^{62}$ HR I, 2, 300.

${ }^{63}$ LAURENT, Störtebeker (wie Anm. 55). S. 85f., S. 98f.; KOPPMANN. Seeräuber (wie Anm. 4), S. $47 \mathrm{f}$.

${ }^{64}$ BRACKER, Nur einer von ihnen (wie Anm. 5), S. 40-42; BRACKER. Seeraub (wie Anm. 12), S. 26f.: NiRRnheim, Hamburg und Ostfriesland (wie Anm. 4), S. 76.

${ }^{65}$ HR I, 4, 453, dazu BRACKER, Seeraub (wie Anm. 5), S. 33.

${ }^{66}$ Richard Hakluyt, The Principal Navigations, Voyages, Traffiques \& Discoveries of the English Nation, London/Toronto/New York 1927, Bd. 1, S. 163-170, als Opfer: S. 167. 168; als Täter: S. 169.

${ }^{67}$ Puhle. Vitalienbrüder (wie Anm. 4), S. 90-95.

${ }^{68}$ Mogren. Burgenbau (wie Anm. 59), S. 632f.; Ernsı DaEnell, Die Blütezeit der deutschen Hanse. Hansische Geschichte von der zweiten Hälfte des 14. bis zum letzten Viertel des 15. Jahrhunderts. Berlin ${ }^{3} 2001$, Bd. I. S. 145.

${ }^{69}$ Puhle, Vitalienbrüder (wie Anm. 4), S. 59: Cordsen, Beiträge (wie Anm. 4), S. 60.

${ }^{70}$ So schon bei LisCH, Beitrag (wie Anm. 18), S. 61. 
die Seiten gewechselt: 1416 jedenfalls hatte er das Amt eines Hauptmanns im schwedischen Nyköpinghus inne. ${ }^{71}$

Es ist nun nicht überraschend, dass professionelle Kämpfer des späten Mittelalters nicht an modernen Maßstäben persönlicher oder gar nationaler Loyalität zu messen sind. Es ist auch ein in der Forschung viel diskutierter Umstand, dass die Gruppen, die wir als „Vitalienbrüder" identifizieren, immer neue Auftraggeber fanden. Da zudem jeder fehdefähige Mann immer auch seine eigenen Händel ausfocht, konnte etwa einen mecklenburgischen Adeligen eine unbeglichene Rechnung aus den Kämpfen gegen den Deutschen Orden 1396-1398 mit gutem Grund dazu bringen, 1403 auf dänischer Seite Gotland zu erobern.

Und die zitierten Beispiele zeigen deutlich, dass die Gewaltprofessionellen der Zeit um 1400 dabei nicht grundsätzlich gesellschaftlich marginalisiert waren. Sie waren zumindest nicht von vornherein „Outlaws“, die allenfalls noch ihre Verrohung zum Geschäft machen konnten, sondern Mitglieder einer Gesellschaft, in der die gewerbsmäßige Gewaltandrohung und Gewaltanwendung nicht an sich entehrend war. Darum blieb den Erfolgreichen unter ihnen der Wechsel in andere Tätigkeitsfelder (und zurück) durchaus offen. Ihren Status büßten sie um 1400 nur dann ein, wenn sie auf Seiten der Verlierer in Gefangenschaft gerieten, die Gewinner keinen taktischen Gewinn aus ihrer Fortexistenz mehr ziehen konnten und niemand sich fand, für sie einzustehen. Selbst dann aber war Ihre Tätigkeit nicht grundsätzlich entehrend: Bekannt ist der Fall des Otto von Thyne, der vor 1400 längere Zeit im Dienst des Grafen von Oldenburg gestanden und wohl mit Gödeke Michels sein Ende gefunden hatte. Um sein Erbe ausdrücklich: want unde ander ghut, de uppe der see gherovet was führte sein Bruder von 1416 bis mindestens 1425 einen langjährigen Rechtsstreit. $^{72}$

\section{Wer gegen wen?}

Die machtpolitische Gemengelage im Nord- und Ostseeraum um 1400

Neben einem tendenziell anachronistischen Verständnis der rechtlichen und gesellschaftlichen Voraussetzungen des Kaperwesens wird unser Bild von den „Vitalienbriidern“" noch von einem zweiten Faktor verdunkelt: von einer vielfach stark eindimensionalen Reduktion der zeitgenössischen machtpolitischen Konstellation. Demnach hätte die Hanse als Einheit und

\footnotetext{
${ }^{7}$ MoGren, Burgenbau (wie Anm. 59), S. $632 \mathrm{f}$.

${ }^{72}$ R. EHMCK. W. VON BIPPEN, (Hg.), Bremisches Urkundenbuch, Bd. 5, Bremen 1902, Nr. 178. Nr. 274; vgl. BRACKER, Seeraub (wie Anm. 129), S. 25: BRACKER; Nur einer von ihnen (wie Anm. 5), S. 34, S. $38 \mathrm{f}$.
} 
tendenziell neutrale Macht in der Ostsee der Auseinandersetzung zwischen Dänemark und Mecklenburg gegenüber gestanden. Im Westen sei sie selbst wiederum neutral und homogen - mit den Machtkämpfen an der südlichen Nordseeküste konfrontiert gewesen. Bei alledem sei es ihr letztlich nur um die Sicherung des Handels gegangen. In der Literatur zu den „Vitalienbrüdern“ werden so Argumentationsmuster der hansestädtischen Quellen reproduziert, obwohl die Forschung die machtpolitischen Konfliktlinien im nordeuropäischen Raum längst mit großer Präzision nachzeichnen kann.

Im Krieg um die Krone Schwedens standen innerhalb der Hanse nicht etwa nur die mecklenburgischen Landstädte Wismar und Rostock gegen den Rest. Vielmehr bedingten die je eigenen strategischen Erwägungen, aber auch die Loyalität gegenüber den jeweiligen Stadtherren ganz unterschiedliche Positionen. Hamburg etwa agierte zumindest nach 1400 in den nordischen Konflikten deutlich erkennbar als holsteinische Landstadt. und damit de facto als Verbündete des Hauses Mecklenburg - und der von ihm und den Holsteinern engagierten „Vitalienbrüder". ${ }^{73}$ Man wird die Politik der Hansestädte also nur verstehen, wenn man sie zugleich als autonome Akteure, als Mitglied ihres Hansequartiers und als Landstädte begreift ein Bündel von Loyalitäten, das erkennbar schon zeitgenössisch Schwierigkeiten bereitete.

Ebenso sind die Operationen vor allem der Hamburger und Bremer im ostfriesischen Raum selbstverständlich nur zu verstehen auf dem Hintergrund ihrer divergierenden machtpolitischen Interessen in diesem Gebiet und gegenüber dem nach Osten ausgreifenden Grafen von Holland, aber auch dem Grafen von Oldenburg, mit Braunschweig-Lüneburg und dem Bischof von Münster als Machtfaktoren im Hintergrund. ${ }^{74}$ So standen die

${ }^{73}$ Vgl. etwa KRANTZ, Wandalia (wie Anm. 13), Buch X, Kap. 34, zum Krieg zwischen Erich von Dänemark und dem Herzog Heinrich von Schleswig. mit dem der Holsteiner verbündet war (ca. 1420): Die Hamburger namen sich irer. Fuersten mit an, wie billich, vnd fertigten zwoelff grosse Schiffe ab nach der See, deren igliches fuhr auff sein selbst eigen verlust vnd gewinn, hatten von niemandt Soldt noch bestallung, vnd trachteten allein irer beut nach, was sie bekaemen, wollten sie fuer sich haben, schiffien damit vnter Juetlandt vnd erzeigten sich als Feinde. schlugen auch mit den Daehnischen Schiffen. die inen entgegen satzten, vid senckten dauon drey zugrunde, darauff nicht weiniger denn zweyhundert Menschen waren. Ebenda, Buch XI. Kap. 19, S. 389 f.. kommt es zum Friedensschluss zwischen den wendischen Städten und Dänemark, an dem sich Hamburg aus Loyalität gegenüber dem Stadtherren nicht beteiligt.

${ }^{74}$ So schon Ehbrecht, Hansen (wie Anm. 6), S. 62: Ute Scheurlen, Bremen und die Seeräuber, in: BRACKER (Hg.), Die Hanse (wie Anm. 5), Bd. 1, S. 620-626; grundlegend: Seifert, Kompagnons (wie Anm. 54); vgl. NirRnheim. Hamburg und Ostfriesland (wie Anm. 4), besonders S. 11-13; BRACKER, Nur einer von ihnen (wie Anm. 5), S. 30-32, 52f.; Puhle, Vitalienbrüder (wie Anm. 4), S. 105-128; KoppmanN, Vitalienbrüder (wie Anm. 4), S. XX-XXIII; WANKE, Vitalienbrüder (wie Anm. 4), S. 27-34. 
legendenumwobenen Kämpfe der Hamburger gegen die „Vitalienbrüder“ in holländischen und ostfriesischen Diensten im Zusammenhang eines auch von der Elbestadt mit härtesten Bandagen gefochtenen Kaperkrieges von 1399 bis $1403 .{ }^{75}$ Nicht zu Unrecht mussten sich die Hamburger 1400 von den preußischen Städten vorwerfen lassen, sie betrieben in Ostfriesland unter dem Deckmantel der Seeräuberbekämpfung schlicht Machtpolitik. ${ }^{76}$ Und die Bündnispolitik gegenüber einigen ostfriesischen Häuptlingen führte zwangsläufig dazu, dass auch den Bremern und Hamburgern der Vorwurf gemacht wurde, „Seeräuber" zu unterstützen. ${ }^{77}$ Dass die Hamburger die Fehdehelfer des Grafen Albrecht reihenweise als Seeräuber hinrichteten, ist also tatsächlich als Ausdruck einer politisch motivierten Kriminalisierung zu verstehen.

Der Konflikt zwischen den wendischen Hansestädten und Holland steht wiederum im weiteren Kontext der Machtkämpfe im ganzen nordwesteuropäischen Raum, mit England. Frankreich, den Wittelsbachern - Graf Albrecht von Holland war ein Sohn Kaiser Ludwigs des Bayern ${ }^{78}$ - und später Burgund als maßgeblichen Faktoren. ${ }^{79}$ England unterstützte einerseits Dänemark, befand sich andererseits seit den 1380er Jahren in einem mehr oder weniger offenen - und zumal ab etwa 1400 eskalierenden Handelskrieg mit den preußischen Hansestädten. ${ }^{80}$ Die in der Forschung

\footnotetext{
${ }^{75}$ NirRnheim, Hamburg und Ostfriesland (wie Anm. 4), S. 19; Scheurlen, Handel (wie Anm. 4), S. 117 f.; SEIFERT, Kompagnons (wie Anm. 54), S. 158-163.

${ }^{76}$ HR 1. 4, 607, \$11, 608, \$2, 7; vgl. SEIFERT, Kompagnons (wie Anm. 54), S. 159.

${ }^{77}$ Am bekanntesten ist wohl das einschlägige Bekenntnis der „Vitalienbrüder“ im Dienst Widzel tom Brokes im Mai 1398: HR I,4 (wie Anm. 4), 453; vgl. PuHLE, Vitalienbrüder (wie Anm. 4), S. 107; Ehbrecht, Hansen (wie Anm. 6), S. 79; SEIFERT, Kompagnons (wie Anm. 74), S. 150f.; BRACKER, Nur einer von ihnen (wie Anm. 5), S. 30f. Es handelte sich dabei wohl schwerlich um „ein[en] Hohn sondergleichen“, so WANKE, Vitalienbrüder (wie Anm. 4), S. 19, sondern um eine Dokumentation der eigenen fehderechtlichen Stellung, vgl. unten. S. $98 \mathrm{f}$.

${ }^{78}$ Vgl. SEIFERT, Kompagnons (wie Anm. 54), S. 83-86: zur dynastischen Situation: Laetitia Böнм. Das Haus Wittelsbach in den Niederlanden, in: Zeitschrift für Bayerische Landesgeschichte 44 (1981), S. 93-130.

${ }_{77}$ Allgemein grundlegend. SEIFERT. Kompagnons (wie Anm. 54); C. J. ForD, Piracy or Policy. The Crisis in the Channel, 1400-1403, in: Transactions of the Royal Historical Society. 5th Series. Bd. 29 (1979), S. 63-77.

${ }^{80}$ Karl KoppMANN, Die preußisch-englischen Beziehungen der Hanse 1375-1408, in: HGbll. 1883. S. 111-137; Friedrich SchULZ, Die Hanse und England von Eduard III. bis auf Heinrichs VIII. Zeit (Abhandlungen zur Verkehrs- und Seegeschichte, Bd. 5). Berlin 1911, S. 49-68; Stuart JENKS, England, die Hanse und Preußen: Handel und Diplomatie, 1377-1474, Köln u. a. 1992 (QDhG, NF. 38), 3 Bde., hier: Bd. 2, S. 473-533; DERS.. Die preußischen Hansestädte und England, in: Zenon Hubert NowAK. Januz TANDECKI (Hg.), Die preußischen Hansestädte und ihre Stellung im Nord- und Ostseeraum des Mittelalters, Torun 1998, S. 113-131: T. H. LloYD. England and the German Hanse, 1157-1611. A Study of their Trade and Commercial Diplomacy, Cambridge 1991. S. 50-119: Michel M. POSTAN, The Economic and Political Relations of England and the Hanse from 1400 to 1475, in:
} 
den „Vitalienbrüdern“ zugeschriebenen Angriffe auf englische Schiffe in der Nordsee und im Sund konnten also gleichermaßen im Zusammenhang mit der mecklenburgischen Kriegsführung gegen Dänemark wie mit den preußisch-englischen Konflikten stehen.

Die Situation wird nicht übersichtlicher, zieht man in Betracht, dass gerade die Angriffe auf englische Schiffe weniger, wie vielfach angenommen, von Ostfriesland, sondern vielmehr von der südnorwegischen (bzw. heute schwedischen) Küste aus unternommen wurden. Jedenfalls nennen die Klageakten mehrmals den Hafen Marstrand (heute nördlich von Göteborg) als Basis der Kaperei. ${ }^{81}$ Nach „Norwegen“ sollte sich 1400 auch Gödeke Michels mit seinen Leuten retten. Offensichtlich gab es also wie im Bottnischen Meerbusen, ${ }^{82}$ so auch an der Sundküste Rückzugsmöglichkeiten für Gruppen, die wir eher bei den Gegnern der Königin Margarethe vermuten würden.

Im Einzelfall bleiben für den heutigen Betrachter die Verantwortlichkeiten in einem Bündel von Beziehungen undeutlich. Jedenfalls waren diese Konflikte in der Praxis vor allem Handelskriege: Auf allen Seiten operierten Kaperfahrer, sei es im direkten Auftrag, sei es als privatwirtschaftliche Unternehmer oder in nur vager Anbindung an einen Herren.

Dass schon die Beteiligten darüber im Zweifelsfall sprichwörtlich jahrelang streiten konnten, zeigen die Friedens- und Schadensersatzverhandlungen zwischen England und den wendischen und preußischen Hansestädten von 1405 bis $1409 .{ }^{83}$ Aus dem umfangreichen Schriftgut dieser mit allen diplomatischen Finessen geführten Beratungen lässt sich unschwer die Allgegenwart der Kaperei erschließen. Deutlich wird aber ebenso, dass sie nicht nur auf einem gewohnheitsrechtlichen Procedere beruhen, sondern auch auf intensiver Informationssammlung durch die betroffenen Kaufleute, durch Parlament und Hof einer- bzw. die hansestädtischen Instanzen andererseits. Es galt, der jeweils anderen Seite möglichst viele

Studies in English Trade in the 15th Century, hg. von E. Power und Michel M. Postan. London ${ }^{2} 1966$ ('1933), S. 91-153.

${ }^{81}$ Das englische Schadensverzeichnis von 1405 bei HaKLUYT, Principal Navigations (wie Anm. 49), Bd. 2, S. 61-69, verzeichnet für 1394-1395 vor allem Übergriffe vor der norwegischen Küste, darunter die Häfen Courtbuttressow (1x), Longsound (2x), Selaw (1x), Norbern (1x) und Marstrand (4x, alle in 1395): vgl. HR I,4 (wie Anm. 4), 698; EHBRECHT, Einführung (wie Anm. 57), S. 3; Rudolf HOLBACH, Hanse und Seeraub. Wirtschaftliche Aspekte, in: EHBRECHT (Hg.), Störtebeker (wie Anm. 6), S. 131-153, hier: S. 131; Marstrand als Stützpunkt für Übergriffe auf englische Schiffe ist ebenso erwähnt in einem weiteren Schadensverzeichnis von 1407: KUNZE (Hg.), Hanseakten (wie Anm. 54), Nr. 324.

${ }^{82}$ Mogren, Burgenbau (wie Anm. 59).

${ }^{83}$ JenKS, England (wie Anm. 80), S. 534-549; John L. KIRBY, Sir William Sturmy's Embassy to Germany. An Episode in Anglo-Hanseatic Relations in: History Today 15 (1965), S. 29-47; SChulz, England (wie Anm. 80), S. 64-67; Lloyd, England (wie Anm. 80), S. 117-126; KOPPMANN, Beziehungen, S. 135-137. 
Übergriffe nachzuweisen, um sie bei der Berechnung der Ausgleichszahlungen auszustechen.

Den Engländern kam dabei zugute, dass sie gegen die Städte eben jene Rechtsfiktion einer einheitlichen Korporation „Hanse“ als Gesamtschuldner in Stellung bringen konnten, die diese sonst nur aus taktischen Gründen behaupteten. ${ }^{84}$ Jedenfalls gelang es den englischen Gesandten, die Hansequartiere gegeneinander auszuspielen.

Dazu beanspruchten sie nun gegenüber dem dänisch-mecklenburgischen Konflikt Neutralität, wie auch die Hanse als Korporation sie für sich postulierte. Demgegenüber musste die englische Klage notwendig davon ausgehen, dass die beanstandeten Übergriffe Teil einer hansischen Kriegführung gewesen waren. Insofern setzen die Klageakten ihrer Logik nach voraus, dass die beschriebenen Taten eben nicht krimineller "Seeraub“, sondern Überschreitungen des Fehderechts durch Kombattanten waren. Und auch im Kontext der preußisch-englischen Auseinandersetzung machten die Verhandlungen nur Sinn, wenn man für die Übergriffe den Gegner verantwortlich machte, die Täter also nicht als gesetzlose Piraten, sondern als Kombattanten sah. ${ }^{85}$ Doch was sagt dies über den realen Status der Akteure aus? Die Verhandlungsstrategie der Hansestädte lief jedenfalls nicht darauf hinaus, die Angreifer als herrenlose Kriminelle zu identifizieren und so eine eigene Beteiligung zu verneinen. Vielmehr akzeptierten sie die grundsätzliche Zuschreibung der Verantwortlichkeit. Wenn die Städte letztlich also einen erheblichen Teil der Schäden anerkannten, ist dies wohl zumindest auch ein Indiz für tatsächliche Verbindungen. Eine Rolle spielte freilich das auch bei Fehden an Land häufig zu beobachtende Bedürfnis, für die Wiederherstellung des Handelsfriedens eher mehr als weniger zu zahlen. Dennoch lassen sich einzelne Kaperfahrer anhand der Klageakten recht deutlich bestimmten Herkunftsorten und Vernetzungen zuordnen: Ihre Spuren weisen, nicht überraschend, nach Preußen und in die mecklenburgischen Seestädte. ${ }^{86}$

Wenn die Hansestädte also gegenüber England eine Mitverantwortung für den Kaperkrieg dieser Jahre übernehmen mussten, so wurde dabei eine

\footnotetext{
${ }^{84}$ HRUSCHKA, Kriegsführung (wie Anm. 12), S. 166 mit Anm. 519. Schon ab 1395 hatte die Hanse über englische Beschwerden wegen Förderung von Übergriffen beraten müssen, vgl. Koppmann, Vitalienbrüder (wie Anm. 4), S. XVIII; DERS., Beziehungen (wie Anm. 80), S. 123; EHBRECHT, Seeräuber (wie Anm. 6), S. 67; zugleich waren diese Übergriffe engl1schen Schiffern eine willkommene Legitimation für eigene Prisennahmen; vgl. LLOYD, England (wie Anm. 80), S. 52f.

${ }^{85}$ Zur juristischen Bewertung der Schadensersatzverhandlungen vgl. BÖHRINGER. Prise (wie Anm. 29), S. 52-63.

${ }^{86}$ EHBRECHT, Wilfried, Die Ereignisse von 1400/1401/1402 in den Quellen, in: DeRS. (Hg.), Störtebeker (wie Anm. 6), S. 37-56, hier: S. $37 \mathrm{f}$.
} 
schon den Zeitgenossen vielfach kaum durchschaubare Konfliktlage nachträglich auf einen klaren Nenner gebracht. Es wurde also eine juristische Klärung erzwungen, wo zuvor viele Beteiligte mit unklaren Verantwortlichkeiten wohl gut hatten leben können.

Inwiefern sich gerade in der ersten Hälfte des 15. Jahrhunderts im Hanseraum die rechtlichen Maßstäbe und die schriftliche Praxis der Prisennahme veränderten, könnte etwa eine vergleichende Untersuchung der Handelskriege um 1400 mit denen ab den 1420er Jahren verdeutlichen: Zumindest die in den „Hanserecessen“ edierten Quellen legen den Eindruck einer ungleich verstärkten Absicherung der Ausliegerfahrt durch schriftliche Korrespondenzen nahe. ${ }^{87}$

\section{Godes vrende unde al der werlt vyande:}

Die „Vitalienbrüder“ zwischen Zuschreibung und Selbstwahrnehmung

Der einheitliche Kampf „der Hanse“ gegen „die Vitalienbrüder“ ist demnach ein Konstrukt, freilich nicht allein eines der Forschung, sondern schon in den hansischen Quellen der Jahre um 1400 angelegt: Innerhalb wie außerhalb der Hanse trugen verschiedene Akteure ihre Interessengegensätze unter Rückgriff auf autonom agierende Gewaltprofessionelle aus. Um die unterschiedlichen politischen Positionen überbrücken zu können, um verhandlungsfähig zu bleiben, und da dies für die einzelnen Akteure eine Möglichkeit war, ihre je eigenen Interessen als Gemeininteressen zu formulieren, diente in dieser Situation die Idee der „Seeräuber“-bekämpfung als kleinster gemeinsamer Nenner. Die Städte konnten sich über eine gemeinsame Linie in den machtpolitischen Konflikten der Zeit schwerlich einig werden. Dass aber der Handel geschützt werden müsse, war protokollfähig und ließ sich auch als Position gegenüber den kriegführenden Mächten vertreten. Unter dem Rubrum „Seeräuberbekämpfung“ konnte letztlich jede der Städte ihre je eigenen Interessen verfolgen (und auf einen Vorteil gegenüber den Konkurrenten hoffen), ohne den die Hanse konstituierenden Konsensanspruch aufs Spiel zu setzen. Die „Vitalienbrüder“ und ihre Bekämpfung dienten für die Hanse also als gemeinsame Sprachregelung, innerhalb derer interne und externe Konfliktlagen überbrückbar wurden. ${ }^{88}$ Gleichzeitig ermöglichten jedoch die fortgesetzten Konflikte

\footnotetext{
${ }^{87}$ Vgl. etwa die Belege zun Kaperfahrer Marquard Stortebeker aus Wismar: Karl KUNZE (Hg.), HUB, Bd. 6, Leipzig 1905, Nr. 762 mit Anm. 2, Nr. 868; HR 1.8, 512, 758, 779. Einen entscheidenden Schritt zum Schutz von Nichtbeteiligten im Kriegsfall markierte 1427/28 der Beschluss der Städte, beeidigte Schiffspapiere für die neutrale Schifffahrt einzuführen; vgl. BÖHRINGER. Prise (wie Anm. 29), S. 66.

${ }^{88}$ Vielleicht in diesem Sinn hat Rolf Sprandel die Bekämpfung der Vitalienbrüder als
} 
auch die Existenz von Kaperunternehmern immer neu. Dies führte auf absehbare Zeit zu einem sich selbst erhaltenden Wechselspiel: Die postulierte „Seeräuberbekämpfung“ reproduzierte das Problem, statt es zu beseitigen.

In diesem Sinne kann man um 1400 also durchaus einen Prozess der „Kriminalisierung“ beobachten. Dabei wurde jedoch nicht eine etwa zuvor legitime Kaperfahrt zur Piraterie umgewidmet. Vielmehr wurde das fehdetypische unterschiedslose Schadentrachten gegen den Feind und seine Helfer als „Seeraub“ kriminalisiert. Das Kaperrecht als Legitimation der Prisennahme stand erst am Ende dieses Umdeutungsprozesses. Geht es bei der Prisennahme um präzise definierte Konterbande, so will die Fehde den Gegner schlicht durch Schädigung seiner wirtschaftlichen Lebensbedingungen zu einem Einlenken zwingen. Die „Vitalienbrüder“ bewegten sich mitten in diesem Wandlungsprozess - und vielfach fielen sie ihm zu Opfer. Die Delegitimierung der Fehdehilfe als Seeraub führte nämlich in der Summe nicht unbedingt zu einem Zugewinn an Rechtssicherheit oder gar zu einem Rückgang der Gewalt: Man könnte vielmehr umgekehrt annehmen, dass ein zuvor funktionierendes gewohnheitsrechtliches System durchbrochen wurde durch eine neue Differenzierung, die für die jeweils Unterlegenen unmittelbar zu einer Verschärfung der Bedrohung führen musste: Fehdehelfer konnten Opfer von Strafen werden, sie fielen aber nicht notwendig aus der Gesellschaft heraus. Die „Seeräuber“-Terminologie jedoch bedeutete zwangsläufig eine Ausgrenzung des Gegners und damit seine Auslieferung gegenüber ungezügelter Gewalt durch die Sieger.

Professionelle Kämpfer zur See waren also um 1400 nicht grundsätzlich gesellschaftlich marginalisiert. Sie befanden sich aber in einem Wandlungsprozess, in dessen Verlauf sich die Begrifflichkeiten, rechtlichen Kategorien und sozialen Positionen verschoben. Was sich auf der diskursiven Ebene als Durchsetzung der Unterscheidung von illegitimem Seeraub und legitimer Kriegsführung darstellt, bedeutete in der Praxis die Spaltung der Gewaltprofessionellen in zwei Gruppen: Wer militärisch Erfolg hatte und dauerhafte Bindungen an eine Schutzmacht aufbauen konnte, konnte weiter als Kaperer einem ehrbaren Broterwerb nachgehen. Wer langfristig ohne Patronage blieb, dem drohte die Marginalisierung und im Fall der Niederlage die Bestrafung als Seeräuber.

„Propaganda“ aufgefasst: Rolf SPRANDEL, Neuralgische Punkte in der Strafrechtswirklichkeit des Spätmittelalters, in: Dietmar WILLOWEIT (Hg.). Die Entstehung des öffentlichen Strafrechts: Bestandsaufnahme eines europäischen Forschungsproblems, Köln u. a. 1999 (Konflikt. Verbrechen und Sanktion in der Gesellschaft Alteuropas: Symposien und Synthesen, Bd. 1), S. 177-213, hier: S. $196 \mathrm{f}$. 
Der französische Söldnerführer Jean de Gouges hatte sich schon 1362 als l'ami de Dieu et l'ennemi de tout le monde bezeichnet. ${ }^{89}$ Im Mai 1398 nun gaben Vitalienbruider im Dienst des ostfriesischen Häuptlings Widzel tom Broke - nach einem beeindruckenden Angriff auf die Schifffahrt auf dem Swin - dem von ihnen gekaperten Danziger Eggherd Schoeff eine Botschaft an das Brügger Hansekontor mit auf den Weg: Sie seien Godes vrende unde al der werlt vyande, mit Ausnahme der Bremer und Hamburger. ${ }^{90}$ Dass sie letztere damit innerhalb der Hanse in eine unangenehme Situation brachten, ist überliefert..$^{91}$ Doch was sagt dieser Satz über sie selbst? Er war verbunden mit einem Verhandlungsangebot an die Hansestädte, gegen freies Geleit die Schädigung des Kaufmanns einzustellen. Es handelt sich offenbar um einen Versuch Widzel tom Brokes und seiner Leute, mit einem entscheidenden politischen Faktor zu einer Kooperation zu kommen. In fehderechtlichen Begriffen jedoch übernahmen die hier beteiligten Kämpfer - sicherlich nicht die Gesamtheit der „Vitalienbrüder", sondern nur die Einheiten im Dienst tom Brokes - für sich eine Position allgemeiner Friedlosigkeit. Denn ,aller Welt Feind“", das hieß: Wir befinden uns in Fehde mit Jedermann.

Wer erwerbsmäßig prinzipiell für Jeden zu kämpfen bereit ist, der muss wissen, dass er sich damit zugleich prinzipiell Jeden zum Feind macht. Wer im hart umkämpften Seekriegsgeschäft keine langfristigen Loyalitäten aufzubauen im Stande ist, der wird beinahe zwangsläufig in einer marginalen Position enden. Die Professionalisierung der Fehdeführung bedingte also in ihrer eigenen Logik das Moment der Marginalisierung, nicht unmittelbar als Ehrverlust, sondern als Akkumulation von Schadensansprüchen und Anfeindungen. Dieser Mechanismus freilich greift umso stärker, je schwächer die politische und ökonomische Position eines Akteurs ist: Es war die sogenannte „lose parthey", man könnte sagen: das Dienstleistungsproletariat des Fehdewesens, das sich die ganze Welt zum Feind machen musste. Wer seinem Herren oder seiner Stadt verbunden blieb, wer sich dauerhaft die politische Deckung eines Fürsten, einer Stadt oder gar der Hanse sicherte, der behielt Freunde, und damit eine Rechtsstellung.

Das von Eggherd Schoeff übermittelte Verhandlungsangebot wäre demnach ein Versuch, genau diesem Mechanismus der Ausgrenzung zu ent-

\footnotetext{
${ }^{89}$ Cordsen, Beiträge (wie Anm. 4), S. 26.

${ }^{90}$ HR I,4 (wie Anm. 4), 453.

"Bracker, Seeraub (wie Anm. 5), S. 33; Scheurlen, Handel (wie Anm. 4), S. A25; WANKE, Vitalienbrüder (wie Anm. 4), S. 19f.; PUHLE, Vitalienbrüder (wie Anm. 4), S. 107; EHBRECHT, Hansen (wie Anm. 6), S. 79; BRACKER. Nur einer von ihnen (wie Anm. 5), S. $30 \mathrm{f}$.
} 
gehen. Dass die Städte es nicht annahmen, war allerdings sicherlich keine grundsätzliche Entscheidung, es war eine Frage der politischen Opportunität - und im Fall der Bremer und Hamburger wohl auch des Opportunismus.

Der Begriff „Vitalienbrüder", soviel lässt sich vor cincr genaueren semantischen Untersuchung vermuten, steht im Kontext des hier beschriebenen Differenzierungsprozesses. Die „Vitalienbrüder“ als Phänomen sui generis im weiteren Kontext der spätmittelalterlichen Seekriegsführung waren so zumindest zunächst eine konsens- und identitätsstiftende Fiktion ihrer Gegner. Ob es sie auch als selbständige Gruppenbildung mit einem spezifischen Selbstverständnis und zumindest dem Anspruch nach klarer Abgrenzung gegenüber anderen Gewaltprofessionellen gegeben hat, müssten weitere Untersuchungen erweisen. Vielleicht führte gerade der beschriebene Prozess der kategorialen Umwertung zur Entstehung der „Vitalienbrüder" als abgrenzbarer Gruppe von Kämpfern. Ob und zu welchen Zeiten sie sich insgesamt oder zumindest in kleineren Einheiten als Rechtsgemeinschaft begriffen, bliebe zu klären.

Grundsätzlich war jede Schiffsbesatzung genossenschaftlich organisiert. $^{92}$ Im Rahmen der Kriegführung übertrug sich diese institutionelle Struktur sicher auch auf größere Gruppen, die dann mehr oder weniger langfristige Loyalitätsbindungen ausbildeten. Man kann vermuten, dass es zwischen verschiedenen Gruppen, die ja alle dem gleichen Broterwerb nachgingen, auch durchaus engere Kommunikation gegeben haben dürfte. ${ }^{93}$ Vor 1391 hatten die Kapertruppen mehrmals selbständig Waffenstillstandsverträge geschlossen, waren also als autonomer politischer Faktor greifbar geworden. ${ }^{94}$ Seit den Neunziger Jahren hingegen operierten ,Vitalienbrüder" bei allen kriegführenden Parteien auch gegeneinander, ohne dass eine überwölbende genossenschaftliche Integration erkennbar würde.

\footnotetext{
${ }^{92}$ Klaus FRIEDLAND, Schiff und Besatzung. Seemännische Berufsgemeinschaften im spätmittelalterlichen Nordeuropa, in: DERS., Mensch und Seefahrt zur Hansezeit (QDhG, N.F., Bd. 42), Köln 1995, S. 256-267, hier: S. 260f.

${ }^{93}$ Zum korporativen Gruppenbewusstsein von Söldnern bzw. Landsknechten im 16. Jahrhundert vgl. etwa: Matthias ROGG, „Ein Kriegsordnung neu gemacht" - Die Entstehung, Aufgabe und Bedeutung militärischer Funktionseliten im 16. Jahrhundert, in: Sozialer Aufstieg. Funktionseliten im Spätmittelalter und in der frühen Neuzeit, hg. von Günther ScHULz (Deutsche Führungsschichten in der Neuzeit, Bd. 25), München 2002, S. 357-386, hier: S. 377.

${ }^{94}$ BRACKER. Seeraub (wie Anm. 12), S. 10; im Gegensatz zum hier Gesagten stellt PUHLE, Söldner (wie Anm. 14) die These auf, dass es gerade nach $1395 \mathrm{zu}$ einer Gruppenbildung gekommen sei.
} 


\section{Die Fakten hinter der Fiktion:}

\section{Zum historischen Hintergrund der Störtebeker-Legende}

In der wissenschaftlichen Forschung, ebenso in der populären Geschichtswahrnehmung abseits der besonders kruden Legendenbildungen, sind die „Vitalienbrüder" eine mehr oder weniger organisierte Bruderschaft von Kaperfahrern bzw. Seeräubern. Und zumindest ab etwa 1395 gilt als einer ihrer wichtigsten, wenn nicht der wichtigste Anführer Klaus Störtebeker. Er wird in der Regel zu einer zweiten Generation der Vitalienbrüder gezählt, die nach dem Frieden von Skanör und Falsterbo die zumeist aus dem mecklenburgischen Adel stammenden Schiffsführer ersetzt hätte. Da 1380 ein Nicola/us] Stortebeker im Verfestungsbuch der Stadt Wismar als Opfer einer Prügelei erwähnt wird, ${ }^{95}$ geht man davon aus, dass er durch die Beteiligung seiner Heimatstadt am mecklenburgischen Kaperkrieg gegen Dänemark zu den „Vitalienbrüdern“ gestoßen und dann zu einem Anführer geworden sei. ${ }^{96}$ Von 1394 bis 1399 erwähnt das bereits erwähnte englische Schadensverzeichnis von 1405 neben anderen Kapitänen mehrmals auch Storbiker, one called Strotbeker bzw. Stertebeker. ${ }^{97}$

Im August 1400 urkundet Graf Albrecht von Holland über einen mit Vitalienbrüdern geschlossenen Vertrag: Acht Schiffsführer nehme er in Geleit, darunter einen Johan Stortebeker, dazu 114 Mann Besatzung van hore gemeenre vitaelgebrodere wegen. Diese voerscreven vitaelgebroeders sollen, so die Urkunde, vyant wesen alle de genre, die onse vyande siin, nämlich den Ostfriesen von Westergo und Ostergo, den Groningern, den Hamburgern und allen anderen, die jenseits der Lauwers wohnen und gegen die er, der Graf, mit Recht Fehde führe. Schiffe und Gut, das sie von den Feinden nähmen, dürften sie in die Grafschaft einführen und frei darüber verfügen. Von seinen Untertanen sollen sie nicht verfolgt werden. Gültig solle diese Kaperlaubnis für ein Vierteljahr sein, bei vorzeitiger Kündigung für 14 Tage nach einem schriftlichen Widerruf. Dies alles schließlich wurde om der meere zekerheit willen besiegelt vom Grafen und diversen seiner Lehnsleute. ${ }^{98}$ Dieser ausdrücklich als „Vitalienbruder“ be-

${ }^{95}$ Stadtarchiv Wismar, Verfestungsbuch der Stadt Wismar, zu 1380: Item Balhorst, Boldelaghe et Craan eo, quod Gherardo seruo Poppen et Nicolao Stortebeker cuilibet ossis fracturam cum v. blauiis [...] intu[l]erunt tempore noctumo. Vgl. dazu PUHLE. Vitalienbrüder (wie Anm. 4), S. 23f., S. 88: BRACKER, Nur einer von ihnen (wie Anm. 5), S. 16f., KopPMANN, Seeräuber (wie Anm. 4), S. 18.

${ }^{96}$ Puhle. Vitalienbrüder (wie Anm. 4), S. $72 \mathrm{ff}$., S. $88 \mathrm{f}$.

${ }^{97}$ HaKluYt, Principal Navigations (wie Anm. 49), Bd. 2, S. 59-71; vgl. BRACKER, Nur einer von ihnen (wie Anm. 5), S. 46-49; PuHLE, Vitalienbrüder (wie Anm. 4), S. 10; und schon LAURENT, Störtebeker (wie Anm. 55), S. 70.

${ }^{98}$ HR I,4 (wie Anm. 4), 605: Haarlem, 1400 Aug. 15. 
zeichnete Johan Stortebeker nun wird in der Forschung heute mehrheitlich als identisch mit dem „Klaus Störtebeker" der weiteren Überlieferung und der Legende gesehen. ${ }^{99}$

Denn abseits dieser drei archivalischen bzw. urkundlichen Belege hat sich die Literatur bisher nur auf chronikalische Übcrlicfcrungen stützen können. Herangezogen wurde dabei als angeblich älteste Überlieferung in der Regel die sogenannte Lübecker Rufus-Chronik, entstanden zwischen 1430 und $1438 .^{100}$ Sie schreibt zum Jahr 1402:

In deme sulven jare vochten de Engelandesvarer van der stad Hamborch uppe der zee myt den zeeroveren, de syk vitalyenbroder nomeden, unde behelden den seghen jeghen se. Se slughen erer beh den 40 doet by Hilghelande unde vinghen erer by 70. De brachten se myt syk to Hamborch, unde leten en allen de hovede afslan; ere hovede setten se by de Elve up eyne wisch, to eyme tekene, dat se de zee gherovet hadden. Desser vitalien hovetlude weren ghenomet Wichman und Clawes Stortebeker. ${ }^{101}$

Kurze Zeit später, so Rufus, hätten die Hamburger auch noch Godeke Michels unde Wygbold, ein meyster an den seven kunsten mit 80 Mann geschlagen, nach Hamburg gebracht und hingerichtet. Das Ende des Gödeke Michels ist denn auch in den Kämmereirechnungen der Stadt Hamburg, im hansischen Schriftverkehr und durch verschiedene Auseinandersetzungen um die Beute gut dokumentiert. ${ }^{102}$ Und auch die von "Rufus“ beschriebene erste Schlacht hat in den Hamburger Kämmereirechnungen ihren Niederschlag gefunden. ${ }^{103}$ Allein: Die Namen der unterlegenen „Vitalienbrüder“ werden in diesem Fall nicht genannt. Die Erwähnung bei „Rufus" und die Urkunde des Grafen von Holland werden jedoch in aller Regel als sichere Indizien gewertet für die grundsätzliche Authentizität der ja auch in der populären Überlieferung konkurrenzlosen Annahme, dass die Hamburger Klaus Störtebeker bei Helgoland besiegt und am Ufer der Elbe hingerichtet hätten. ${ }^{104}$ Und obwohl zumeist nicht verschwiegen wird,

\footnotetext{
${ }^{99}$ BraCker, Nur einer von ihnen (wie Anm. 5), S. 52; SCHEURLEN, Handel (wie Anm. 4), S. $117 \mathrm{f}$.

${ }^{100}$ PUhLE, Vitalienbrüder (wie Anm. 4), S. $130 \mathrm{f}$; KOPPMANN, Seeräuber (wie Anm. 4), S. 39-42, Postel, Pirat (wie Anm. 20), S. 61.

${ }^{101}$ Karl KoppManN (Hg.), Die Chroniken der niedersächsischen Städte, Lübeck, Bd. III (Die Chroniken der Deutschen Städte, Bd. 28), Leipzig 1902 Nr. XVI: Der sog. RufusChronik 2. Theil, 1395-1430, S. 1-342, hier: \$1150, S. $25 \mathrm{f}$.

${ }^{102}$ Vgl. KoppMAnN, Seeräuber (wie Anm. 4), S. 39f., S. 45-48; PuHLE. Vitalienbrüder (wie Anm. 4), S. 139-142; BRACKER. Nur einer von ihnen (wie Anm. 5), S. 33f., 44-52; BRACKER, Seeraub (wie Anm. 12), S. 3 If.

${ }^{103}$ PUhle, Vitalienbrüder (wie Anm. 4), S. 10: BRACKer, Seeraub (wie Anm. 12), S. 27-29.

${ }^{104}$ KOPPMANN, Seeräuber (wie Anm. 4), S. 39-49; zusammenfassend: EHBRECHT, Ereignisse (wie Anm. 86). S. 37-57; PUHLE, Vitalienbrüder (wie Anm. 4), S. 134-142; BRACKER, Nur einer von ihnen (wie Anm. 5), S. 41-43, S. 53-56; BRACKER, Seeraub (wie Anm. 12), S. $28 \mathrm{f}$.
} 
dass offenbar zu Lebzeiten etwa einem Gödeke Michels viel größere Bedeutung zugekommen sei, ${ }^{105}$ lassen die meisten Darstellungen mit dem Tod Störtebekers auch die Geschichte der Vitalienbrüder enden - ein deutlicher Reflex der Legende in der Forschungsliteratur. ${ }^{106}$ Umstritten bleibt bei alledem allenfalls die korrekte Datierung der Ereignisse. ${ }^{107}$

Nun stimmen die bei „Rufus“ genannten Namen der vier Schiffsführer nicht mit denen in der Urkunde Albrechts von Holland überein. Zumindest Gödeke Michels und Wigbold allerdings waren im Vorfeld beim Grafen von Oldenburg untergekommen und hatten sich dann nach Norwegen zurückgezogen. ${ }^{108}$ Eventuell waren sie später in den Dienst des Holländers getreten. ${ }^{109}$ Die zuerst von Albrecht engagierten acht Hauptleute mit ihren 114 Leuten jedenfalls müssen nicht identisch sein mit den Gegnern der Hamburger vor Helgoland.

War also Johan Stortebeker nicht unter den in Hamburg Hingerichteten? Es könnte sich ja um eine zweite Person neben Klaus Störtebeker gehandelt haben. ${ }^{110}$ Und tatsächlich hat die Forschung früh auf weitere Träger des markanten Nachnamens hingewiesen: 1439 steht ein Hermen Stortebeker als Söldner im Dienst der Stadt Hamburg. "I 1470 lebt in Wismar ein Hans Stortebeker, später ist hier eine Familie dieses Namens nach-

${ }^{105}$ So schon LaURENT, Störtebeker (wie Anm. 55), S. 70; PUHLE, Vitalienbrüder (wie Anm. 4), S. 149.

${ }^{106}$ Puhle, Vitalienbrüder (wie Anm. 4), S. 143-145; vgl. auch Überblicksdarstellungen wie etwa: Bohn, Piraten (wie Anm. 30), S. 11 f.; Philippe Dollinger, Die Hanse, ${ }^{5} 1998$, S. 114 ; Heinz SToob, Die Hanse, Graz/Wien/Köln 1994, S. 209; anders: DaENELl, Blütezeit (wie Anm. 68), S. 355: dagegen jetzt: HRuSCHKA. Kriegsführung (wie Anm. 12), S. 260 f.

${ }^{107}$ Für den Tod Störtebekers: 1400: BRACKER. Nur einer von ihnen (wie Anm. 12), S. 54 (Herbst); KoppmanN, in: Ders., Rufus-Chronik (wie Anm. 101), S. 25, Anm. 7; 1401: KoppMANN, Seeräuber (wie Anm. 4), S. 40-45 (Gefangennahme im Februar, Hinrichtung im Oktober); NiRRNHEIM, Hamburg und Ostfriesland (wie Anm. 4), S. 18f. (Frühjahr); BENTS, Dichtung (wie Anm. 2), S. 53 (Frühjahr); CiESLIK, Mythos (wie Anm. 22), S. 453; SCHEURLEN, Handel (wie Anm. 4), S. 118; PuHLe, Vitalienbrüder (wie Anm. 4), S. 135 (Herbst); EHBRECHT, Seeräuber (wie Anm. 6), S. 67 (Frühjahr); DAENELl, Blütezeit (wie Anm. 68), S. 355 (Frühjahr); STOOB, Hanse (wie Anm. 106), S. 209; 1402: LAURENT, Störtebeker (wie Anm. 55), S. 79f.; vgl. zusammenfassend EHBRECHT, Ereignisse (wie Anm. 86), S. 46.

${ }^{108}$ Johann Martin LAPPENBERG, in: LAURENT, Störtebeker (wie Anm. 55), S. 96.

${ }^{1169}$ HR I, 4, 606: Im November 1400 nimmt Albrecht weitere Vitalienbruider, die sich in Oldenburg aufhalten, in sein Geleit und erlaubt ihnen den Aufenthalt in Staveren, um dieselben Feinde zu schädigen, in diesem Fall ausdrücklich unbefristet, aber mit Kündigungsfrist: Dit sal gedueren een maent lang na onsen wederseggen. Auffällig ist, dass diese große Truppe ohne Führungspersönlichkeiten erscheint, weshalb auch die gräfliche Kanzlei sie nur vage zu bezeichnen vermochte.

${ }^{110}$ So KOPPMANN, Seeräuber (wie Anm. 4), S. 39: ,[...] wahrscheinlich ein Verwandter oder Namensvetter [...]"; ihm folgend: WANKE, Vitalienbrüder (wie Anm. 4), S. 35; ebenso EHBRECHT, Seeräuber (wie Anm. 6), S. 67, Anm. 92.

${ }^{11}$ LAURENT, Störtebeker (wie Anm. 55), S. 86; Carl WALTHER, Über den Namen Störtebeker, in: Mitteilungen des Vereins für Hamburgische Geschichte 1 (1878), S. 89-94, hier: S. 91 . 
weisbar. ${ }^{112} 1473$ kaperte ein Stortebeke ein Schiff aus Middelburg und gab sich dabei als Hamburger Auslieger aus, was von der Stadt jedoch zurückgewiesen wurde. ${ }^{13} 1566$ wurde in Schwerin gar ein Clauß Stortebeker Neubürger. ${ }^{114}$ Hinzuzufügen wäre der - bisher in der Forschung nicht berücksichtigte - Kaperfahrer Marquard Stortebeker aus Wismar, der $1428 \mathrm{im}$ Zusammenhang mit Auseinandersetzungen zwischen den wendischen Städten und Dänemark, bzw. den preußischen Städten und England, mehrfach überliefert ist. ${ }^{115}$

In dem bei Hakluyt überlieferten Schadensverzeichnis werden zu einem Übergriff des Jahres 1399 die Verantwortlichen wie folgt aufgezählt: [...] certaine malefactors of Wismer \& Rostok, and others of the Hans, namely, Godekin Mighel, Henrie van Hall de Stertebeker, with others of their confederates [...]. Wilfried Ehbrecht hat daher de Stertebeker als - unter adeligen „Rovern“ üblichen - Beinamen des Henrie van Hall verstehen wollen. ${ }^{116}$ War dieser also die historische Person, aus der die Legende einen „Klaus Störtebeker" machte? Als Indiz dient einzig ein fehlendes Komma bei Hakluyt. Transkription, Übersetzung und Drucklegung dieser Edition sind jedoch Produkte des 16. Jahrhunderts, man wird also schwerlich philologische Details wie dieses aus ihr ablesen können. Hinzu kommt, dass der Henrie van Hall, der 1399 mit Gödeke Michels und de Stertebeker unterwegs war, sich vielleicht mit einem Hinrik Holle identifizieren lässt, der im Mai 1400 in Emden von den Hamburgern hingerichtet wurde. ${ }^{117}$

Die Kapervereinbarung Albrechts von Holland und die Namensnennungen in den englischen Schadensverzeichnissen bei Hakluyt wurden bisher also ausschließlich mit einem „Klaus Störtebeker" identifiziert, für den es ansonsten nur einen archivalischen Beleg gibt: Die Notiz im Wismarer Verfestungsbuch von 1380, die sich zwar pittoresk in unser Bild fügt, aber letztlich nur eine geringen Quellenwert für die Suche nach einem Kaper-

112 LAURENT, Störtebeker (wie Anm. 55), S. 86f.; WALTHER, Namen (wie Anm. 111), S. 91; CiesLik, Mythos (wie Anm. 22), S. 455.

${ }^{113}$ HUB 10, 218, 228; EhBRECHT, Einführung (wie Anm. 57), S. 11. CiesLIK. Mythos (wie Anm. 22), S. 457, nennt ihn „Klaus Störtebeker“; nach BENTS, Dichtung (wie Anm. 2), S. 121 nehmen Cieslik und Postel, Pirat (wie Anm. 20), S. 63, an, es handele sich um einen bewusst gewählten Kampfnamen, also ein Zeugnis der Heldenverehrung in Seeräuberkreisen: ZimmERLiNG, Störtebeker (wie Anm. 2), S. 321 ff., behauptet zudem, ein Hamburger Schiff sei das Opfer gewesen; ebenso PuHLE, Vitalienbrüder (wie Anm. 4), S. 161.

114 EHBRECHT, Ereignisse (wie Anm. 86), S. 37.

${ }^{115}$ HUB 6, 762, 868 (ohne Vornamen); HR I, 8, 512, 758, 779.

${ }^{116}$ EHBRECHT, Ereignisse (wie Anm. 86), S. 37, Anm. 5; das fehlende Komma stillschweigend emendiert haben: LAURENT. Störtebeker (wie Anm. 55), S. 70, Anm. 45: BraCKER. Nur einer von ihnen (wie Anm. 12), S. 49.

${ }^{117}$ HR I, 4, 591, 638; vgl. dazu Carl WOEBCKEN. Störtebeker, in: Archiv für Landes- und Volkskunde von Niedersachsen 3 (1942), S. 129-156, hier: S. 140. 
fahrer der Jahre um 1400 hat. Vor allem aber hat die Forschung schon früh auf die Existenz eines Danziger Schiffers Johann Strotebeker hingewiesen. Freilich wurde er, da er nach den traditionsstiftenden Helgoländer und Hamburger Ereignissen des Jahres 1400/01 noch mehrmals überliefert ist, für die Suche nach der historischen Person hinter der Legende nicht herangezogen. ${ }^{118}$ Nicht beachtet wurde dabei, dass Johann Strotebeker nicht nur als Kauffahrer, sondern auch als Kaperkapitän archivalisch überliefert ist: Im November 1405, so eine weitere englische Klageakte aus dem Jahr 1407, kaperten Johannes Strotebeker de Danczik und sieben Genossen im norwegischen Sellowe das Schiff le Petre aus King's Lynn und entnahmen daraus - injuste ceperunt, spoliaverunt et asportaverunt - diverse Waren verschiedener Kaufleute. ${ }^{119}$ Es ist nun quellenkritisch kein Grund ersichtlich, die Operationen des Storbiker / one called Strotbeker / Stertebeker von 1394 bis 1399 gegen englische Schiffe nicht diesem 1405 im gleichen Seegebiet gegen die gleichen Gegner und teilweise mit den gleichen Kompagnons $^{120}$ tätigen Kaperfahrer zuzuschreiben, zumal beide Quellen im Kontext der gleichen diplomatischen Auseinandersetzung stehen. Es ist weiterhin nur zu augenfällig, dass dieser Johannes Strotebeker de Danczik auch der gleichnamige Empfänger der holländischen Kapererlaubnis vom August 1400 gewesen sein dürfte, da er vorher und hinterher im gleichen Operationsraum nachweisbar ist.

Gegen diese Zuschreibung spricht - außer der traditionsstiftenden Bedeutung der Legende - nur der Bericht über die angebliche Hinrichtung eines „Klaus Störtebeker" in der chronikalischen Überlieferung. Freilich ist doch für ereignisgeschichtliche Fragen grundsätzlich von einem höheren Quellenwert archivalischer Quellen gegenüber den Produkten der späteren Geschichtsschreibung auszugehen. Die Schadensverzeichnisse der englischen Kaufleute zeichnen sich zudem durch eine große Präzision der Angaben aus, wollte man doch in fehde- und seerechtlich offenbar sehr umstrittenen Verhandlungen einen diplomatischen und pekuniären Erfolg erreichen. Daher ist etwa ein Nebeneinander zweier gleichnamiger Akteure ohne spezifizierende Identifikation zumindest unwahrscheinlich, zumal

\footnotetext{
${ }^{118}$ So schon Walther. Namen (wie Anm. 111), S. 91. Anm. 1; KopPMANN, Bezichungen (wie Anm. 80), S. 126; vgl. EHBRECHT, Ereignisse (wie Anm. 86), S. 37; neuerdings: Stuart JENKS, Das Danziger Pfundzollbuch von 1409 \& 1411 (Edition auf CD-Rom), dazu: Anleitung und Einleitung in: HGbll. 124 (2006). S. 115-158, hier: Personenregister, s. v.: „Storczebecher. Hannes": „Wohl nicht mit dem Vitalienbruder Johan Stortebeker identisch [...]“.

${ }^{119}$ KUNZE (Hg.), Hanseakten (wie Anm. 54), Nr. 325: Neue Klageartikel der Engländer (vom Jahr 1407).

${ }^{120}$ So ist 1405 auch Klaus Scheld noch nachweisbar, KUNZE (Hg.). Hanseakten (wie Anm. 54). Nr. 324, der schon vor 1400 als Kompagnon Gödeke Michels' und Störtebekers überliefert ist, vgl. etwa HaKLUYT, Principal Navigations (wie Anm. 49), S. 61.
} 
die Überlieferung den Schluss zulässt, dass unser Protagonist einen erheblichen Bekanntheitsgrad erworben hatte. ${ }^{121}$ Vor allem aber lässt sich im vorliegenden Fall präzise nachzeichnen, wie die verderbte Benennung der historischen Person und damit der Ursprung der Legende in die Überlieferung eingedrungen sind. ${ }^{122}$

So bleibt nur eine Möglichkeit: Der Nicola[us] Stortebeker, der 1380 in Wismar Opfer einer Prügelei wurde, ist nicht identisch mit dem späteren Kaperfahrer. Das Schadensverzeichnis zu den Jahren 1394-1399 nennt diesen durchweg ohne Vornamen und im Zusammenhang mit den mecklenburgischen Kaperfahrern aus Wismar und Rostock. ${ }^{123}$ Schon diese Übergriffe gegen den englischen Handel mit dem Reich Margarethes könnten freilich auch von den preußischen Städten gedeckt worden sein. Denn nach 1400 erscheint er als Danziger. Da er sich 1398 und 1399 (nicht aber 1397) in der Nordsee nachweisen lässt, ist eine Teilnahme etwa an den Kämpfen um Gotland eher unwahrscheinlich. ${ }^{124}$ Wenn doch, so könnte er freilich gleichermaßen auf Seiten seiner vormaligen mecklenburgischen Auftraggeber oder auf Seiten seiner (späteren?) preußischen Heimatstadt, d.h. auf Seiten der Deutschordensflotte teilgenommen haben. ${ }^{125} \mathrm{Er}$ ist jedenfalls in den Jahren ab 1394 archivalisch nicht in Ostfriesland, wohl aber an der norwegischen (heute schwedischen) Sundküste nachweisbar - er kann freilich unschwer auch in Ostfriesland aktiv gewesen sein. Immerhin hat er im Herbst 1400 im Auftrag des Grafen von Holland gegen die Hamburger kämpfen sollen. Ob er an der Niederlage des Jahres 1400 oder 1401 beteiligt war, wissen wir nicht. Sicher aber ist, dass er nicht in Hamburg hingerichtet wurde.

Stattdessen betätigte er sich noch mehr als ein Jahrzehnt später als Kauffahrer und Kaperunternehmer auf Nord- und Ostsee. Bevor er im November 1405 mit seinen Genossen die le Petre kaperte, war er schon mit einem anderen Delikt gerichtsnotorisch geworden: Im April 1405

${ }^{121}$ So wird in der Klageschrift zu 1405 bei den einzelnen Punkten statt der Liste der acht Täter nur noch wiederholt: [...] dictus Johannes Strotebeker et socii sui predicti [...], KUNZE (Hg.), Hanseakten (wie Anm. 54), Nr. 325. Freilich wird der letzte der Liste unter Nr. 1 bezeichnet als: Nicholaus van der Selle de eadem, principalis malefactor et omnium spoliacionum gubernator. Er hatte also sicherlich eine größere Prominenz erworben, während Johannes Strotebeker vielleicht eher als erster der Namenseinträge mechanisch wiederholt wurde.

${ }^{122}$ Siehe unten, S. 108-117.

${ }^{123}$ Hakluyt, Principal Navigations (wie Anm. 49), S. 61: [...] one Goddekin Mighel, Clays Scheld, Storbiker, and divers others of Wismer and Rostok, and of the Hans [...].

${ }^{124}$ Dies wird insbesondere in populären Verarbeitungen immer wieder angenommen.

${ }^{125}$ Zur Beteiligung der preußischen Städte an der Invasion Gotlands durch den Deutschen Orden vgl. Friedrich BENNINGHOVEN, Die Gotlandfeldzüge des Deutschen Ordens 1398-1408, in: ZfO 13 (1964), S. 421-477, hier: S. 433. 
nämlich hatten die preußischen Städte auf der Marienburg über die Einhaltung eines Boykotts gegen England verhandelt. ${ }^{126}$ Zwei Danziger Kapitänen warf man vor, die Handelssperre durchbrochen zu haben, nämlich Claus Cordis und dem schipherre Stortzebechir. Für Letzteren bürgte Arnold Rogge, borger czu Danczk, bis er von einer in der Zwischenzeit angetretenen Wallfahrt nach Rom wieder heimgekehrt sei. ${ }^{127}$ Es könnte sich dabei um eine vom Danziger Gericht verhängte Strafwallfahrt handeln, ${ }^{128}$ oder auch um einen Versuch, bis zu einer Abkühlung der Situation in Deckung zu gehen. Im August 1405 jedenfalls waren beide Boykottbrecher noch nicht wieder aufgetaucht. ${ }^{129}$

$\mathrm{Ob}$ er die beschwerliche Reise überhaupt angetreten hatte, bleibt zweifelhaft, da er ja in der Zwischenzeit auch vor der norwegischen Küste aktiv wurde. Im Frühjahr war er wieder in Danzig: Im März 1406 musste der schiphere Stortzebechir neben anderen Schmugglern 25 Mark Strafe an die Städte und 23 englische Nobel an seine Heimatstadt zahlen. ${ }^{130}$ Sie standen mit ihrem Vergehen nicht allein: Immerhin hatte sogar Johann Gotke, Sendbote der Städte in England, während der Handelssperre auf seiner diplomatischen Reise Tuchhandel betrieben. ${ }^{131}$

Ein Kaperunternehmen gegen englische Schiffe und der Bruch einer Handelssperre gegen England - das war offensichtlich kein Widerspruch. Erst recht sprach offenbar nichts gegen eine Tätigkeit als Kauffahrer: Zwischen Mai und August 1409 zahlte Sthorczebecher bzw. Hannes Storczebecher insgesamt viermal den Danziger Pfundzoll, jeweils für große Schiffe von 100 bzw. 120 Last. Zweimal verzollte er vor allem Holz und Wachs, zweimal Tuche (terling). ${ }^{132}$ Der gerade erschienenen Edition des Pfundzollbuches von Stuart Jenks verdanken wir auch die Information,

\footnotetext{
${ }^{126}$ KoppManN, Beziehungen (wie Anm. 80), S. $125 \mathrm{f}$.

${ }^{127}$ HR I,5, 241, §12 und 13: Recess zu Marienburg, 1405 Apr. 5: Unde deme ez tag gegeben bys czum nesten tage, das dy stete wider czusampne komen werden, denne Stortzebechir czu stellen, ab her bynnen des von de[r] Romeschen reyse wirt komen, adir czu lyden denne, was em dy stete werden czusprechen.

${ }^{128}$ SPRANDEL, Neuralgische Punkte (wie Anm. 88). S. 192f.; L. CaRlen, (Art.) Strafwallfahrten, in: HRG V (1998), Sp. 17-19.

${ }^{129}$ HR I, 5, 260: Recess zu Marienburg, 1405 Aug. 10: Item Claus Cordis und Stortebeker sullen zelbir adir ire borgen czu dem nesten taghe komen, ire sache denne tzu enden.

${ }^{130}$ HR I, 5, 308: Recess zu Danzig.

${ }^{131}$ HR I, 5, 308: Recess zu Danzig, 1406 März 22, Nr. 9; vgl. HR 1,5, 170; und KOPPMANN, Beziehungen (wie Anm. 80), S. 126.

132 JENKS (Hg.), Pfundzollbuch (wie Anm. 118), Nr. 140 (Tuche verschiedener Kaufleute), Nr. 256 (Asche, Holz, Wachs verschiedener Besitzer), Nr. 1029 (Tuch), Nr. 1424 (Asch, Teer, Holz); nach JENKS. S. 140, Tabelle 8, lassen sich die Einträge wie folgt datieren: Nr. 140: ca. 07. Mai; Nr. 256: 14. Mai; Nr. 1029 und 1424: zwischen 14. Mai und 10. August; vgl. die Erläuterungen Jenks', S. $140 \mathrm{ff}$., zu den saisonalen Schwerpunkten des Danziger Handels; zum Begriff terling vgl. ebenda, Sachregister, s.v. ,terling“.
} 
dass in Danzig gleichzeitig ein George Storzcebecher im Salzhandel aktiv war. ${ }^{133}$ Und Jenks ergänzt aus englischen Quellen, dass Hannes Storczebecher mit seinem Schiff Marienknyght de Dansk - also wohl: „Marienknecht" oder „Marienritter" - Handel mit London und Scarborough getrieben habe. ${ }^{134}$

Tatsächlich war unser Schiffer mit den Marienrittern des Deutschen Ordens im Geschäft: Im Jahr 1411 hielt die Großschäfferei Königsberg Anteile an dem schiffe, das Sto[e]rtczbechir furt. Außerdem hatte er Geld bei der Schäfferei aufgenommen, das er bis Weihnachten 1419 zurückzahlen musste. ${ }^{135}$

Freilich müssen diese Nachrichten nicht einen Rückzug ins Zivilleben bedeuten: Nahm doch im September 1413 König Heinrich V. von England Joh. Strottebeker, Kapitän eines Holks aus Danzig, mit seinen 40 Männern für den Verkehr mit England auf ein Jahr in Schutz und Geleit. ${ }^{136}$ Eine Besatzung von 40 Leuten war nun für die Führung eines Holks nicht notwendig. ${ }^{137}$ Waren hier neben dem nautischen Personal auch Kämpfer an Bord? Und der Ausstellung eines Geleitbriefes könnte ein Konflikt vorhergegangen sein. War Johann Stortebeker bei einem Kaperunternehmen in englische Gefangenschaft geraten, hatte er Urfehde schwören müssen, um sich auszulösen, und wurde er nun unter königlichen Schutz gestellt, um gegen etwaige Vergeltungsbestrebungen abgesichert zu sein? Oder musste er sich für seine Fahrten in englischen Gewässern mit militärischer Bemannung und Geleitschutz absichern, weil er sich in den Jahrzehnten zuvor Gegner gemacht hatte?

Das bewegte Leben des Johann Stortebeker aus Danzig steht so exemplarisch für die Grauzone, in der sich Seefahrt und Seekriegsführung an der Wende zum 15. Jahrhundert bewegten. Das Meer war de facto noch ein rechtsfreier Raum. Wer sich in ihm bewegte, hatte große Chancen, aber auch große Risiken zu gewärtigen, er hatte gewohnheitsrechtliche

${ }^{133}$ JENKS (Hg.), Pfundzollbuch (wie Anm. 118), Nr. 1278 (als Besitzer eines Ladungsanteils); vgl. ebenda. Personenregister, s.v. "Storczebecher, George“"

${ }^{134}$ JenKs (Hg.), Pfundzollbuch (wie Anm. 118), Personenregister, s.v. „Storczebecher“ bzw. „Hannes Storczebecher“. Weiteren Aufschluss könnten ohne Zweifel die von Jenks angeführten Londoner Quellen bieten. Die Bezeichnung „Marienknecht“ könnte sich ebenso auf den Serviten-Orden (Ordo Servorum Beatae Mariae Virginis, „Marienknechte“) bezogen haben, vgl. LexMa 7, Sp. 1793-1795. Bei einem Danziger Schiff ist freilich die Assoziation zum Deutschen Orden naheliegender.

${ }^{135}$ Carl SATTLER (Hg.), Handelsrechungen des Deutschen Ordens, Leipzig 1887: Rechnungen der Großschäfferei Königsberg (S. 99-316): Rechnungsbuch von 1411-1423, S. 293.

${ }^{136}$ KUNZE (Hg.), HUB 5, 1109 (Regest): 1413 Sept. 21, Westminster.

${ }^{137}$ Detlev ElLMERS, Die Schiffe der Hanse und der Seeräuber um 1400, in: EHBRECHT (Hg.), Störtebeker (wie Anm. 6), S. 153-168, hier: S. 160f., geht von etwa zehn Mann nautischer Besatzung für ein durchschnittliches Handelsschiff aus, für die größeren Holke von unwesentlich mehr. 
Normen einzuhalten, die sich zusehends verfestigten. Er wurde dadurch aber nicht selbst zum Rechtlosen: Auch Verstöße gegen die ungeschriebenen Regeln der Schifffahrt waren an Land verhandelbar, ohne einen Ehrverlust nach sich zu ziehen. Je mehr jedoch die Städte und Fürsten das Meer als Rechtsraum durchdrangen, je mehr sie die Unterscheidung von Raub und Prisennahme etablierten, desto mehr entstand für die Seefahrer die Gefahr, wirklich zu „Outlaws“ gemacht zu werden: Je weniger die See rechtsfrei war, desto mehr drohte den Gewaltprofessionellen die Rechtlosigkeit. Johann Stortebeker betraf dieser Prozess noch nicht. Bald nach seinem letzten überlieferten Auftreten jedoch begann die Legendenbildung um seine Person. An ihr lässt sich ablesen, wie sich im hansestädtischen Wahrnehmungshorizont die Gewichte verschoben: Professionelle Kämpfer wurden bei gleicher Tätigkeit je nach Konstellation einerseits als reguläre Kaperfahrer in die Ausbildung frühmoderner Staatlichkeit integriert, andererseits als kriminelle Seeräuber ausgeschlossen. Aus Johann Stortebeker wurde in der hanseatischen Legende der gefürchtete Pirat, aus seinem Kollegen Simon von Utrecht der gefeierte Seeheld.

\section{Die Legende als Produkt der Geschichtsschreibung: Zur Entstehung des Störtebeker-Mythos}

In seinen für die Forschung bis heute maßgeblichen Quellenstudien hatte Karl Koppmann zunächst die Chronik des sogenannten „Rufus“ als erste Überlieferung für den Namen „,Klaus Störtebeker" angenommen. ${ }^{138}$ Die Wissenschaft ist ihm darin gefolgt, ${ }^{139}$ obwohl Jakob Schwalm schon 1895 darauf hingewiesen hatte, dass die Chronik des „Rufus“ zum allergrößten Teil auf einer Fassung der „Chronica novella“ des Hermann Korner (sogenannte Fassung KC) beruht. ${ }^{140}$ Karl Koppmann hat dies in seiner Edition der Rufus-Chronik 1902 übernommen und detailliert nachgewiesen - allerdings im Kleingedruckten, wo es die weitere Störtebeker-Forschung übersehen hat. ${ }^{141}$

Hermann Korner, um 1365 in Lübeck geboren, 1386 bei einer Fehde seiner Stadt als Führer eines Söldnerhaufens erstmals aktenkundig geworden, war vor 1400 in den Dominikanerorden eingetreten. Nach Stationen in Halberstadt, Hamburg und Magdeburg wurde er 1417 Lesemeister im Lübecker Burgkloster. 1431 begann er an der Erfurter Schule seines Or-

\footnotetext{
${ }^{138}$ KOPPMANN, Sceräuber (wie Anm. 4), S. 39-42; zur Verfasserfrage vgl. Jakob SCHWALM (Hg.), Die Chronica Novella des Hermann Korner, Göttingen 1895, S. XXXII-XXXIV.

${ }^{139}$ Mit Ausnahme von: Puhle, Vitalienbrüder (wie Anm. 4), S. 162.

${ }^{140}$ SChwalm (Hg.), Korner (wie Anm. 138), S. 345, Anm. 2.

141 Koppmann (Hg.), Rufus-Chronik (wie Anm. 101), S. 2, Anm. 6.
} 
dens ein Studium, das er 1435 - also im Alter von ca. 70 Jahren - mit dem Doktor der Theologie abschloss. 1438 starb er in Lübeck. ${ }^{142}$ Schon in seiner Magdeburger Zeit (ca. 1410-1414) hatte er mit chronikalischen Arbeiten begonnen. Auf dieser Grundlage verfasste er 1416 eine erste Fassung seiner „Chronica“ (Ká). Bis 1420 überarbeitete er diese zur "Chronica novella" (KA). Um 1423 entstand eine weitere Redaktion (KB), um 1430 eine heute nicht mehr erhaltene (KC), 1435 schließlich die „Chronica novella de quarto opere“ (KD). Auf dieser beruht auch eine deutsche Fassung $(\mathrm{KH})$, deren Bearbeitung Korner kurz vor seinem Tod beendete. Überliefert sind einige weitere Abschriften und Redaktionen von der Hand des Verfassers. Denn die Chronik des Dominikaners war schon zu seinen Lebzeiten ein beliebter Lesestoff in der Lübecker Oberschicht. Sie wurde so zu einer der wichtigsten Grundlagen für die Geschichtsschreibung der Stadt und ihrer Umgebung. ${ }^{143}$ Man bat Korner um Abschriften, und dieser nutzte jede Gelegenheit zu ändern, zu ergänzen, zu redigieren. Ältere Fassungen und seine Materialsammlungen wurden dabei immer neu herangezogen. Mit fortschreitender Zeit gewann die erzählerische Stilisierung vielfach die Oberhand über die Vorlagen. Der ereignisgeschichtliche Quellenwert also verringert sich in dem Maße, in dem die literarische Ausgestaltung zunimmt. ${ }^{144}$ Mit seinen Vorlagen - vor allem anderen klösterlichen Geschichtsschreibern - ging Korner dabei mit der zeittypischen literarischen Freiheit um. Zur Geschichte seiner Heimatstadt und ihrer Umgebung lagen ihm offenbar bis auf die Chronik des Franziskanerlesemeisters Detmar wenige Unterlagen vor, vielmehr verarbeitete er in erster Linie orale Überlieferungen. Zugang zu Archivalien des Rates dürfte er nicht gehabt haben. ${ }^{145}$

Für Hermann Korners Berichte zu den Vitalienbrüdern jedenfalls sind schriftliche Vorlagen nicht erkennbar. ${ }^{146}$ Zweimal erwähnt die „Chronica

${ }^{142}$ SChwalm (Hg.), Korner (wie Anm. 138), S. III-VII; HruschKA, Kriegsführung (wie Anm. 12), S. 31-35.

${ }^{143}$ Klaus WRIEDT, Bürgerliche Geschichtsschreibung im 15. und 16. Jahrhundert. Ansätze und Formen, in: Peter Johanek (Hg.), Städtische Geschichtsschreibung im Spätmittelalter und in der Frühneuzeit (Städteforschungen, Bd. A 47), Köln 2000, S. 19-50, hier: S. 34f.; HRUSCHKA, Kriegsführung (wie Anm. 12), S. 32 f.

${ }^{144}$ Zur Überlieferungsgeschichte: SCHWALM (Hg.), Korner (wie Anm. 138), S. XVI-XVIII; KopPMAnN (Hg.), Rufus-Chronik (wie Anm. 101), S. XI-XII; HRUSCHKA, Kriegsführung (wie Anm. 12), S. 31. 165: Hruschka bietet im Anhang, S. 339-407, eine umfangreiche Edition bisher unveröffentlichter Abschnitte aus der deutschen Fassung (KH bzW. KW).

${ }^{145}$ SCHWALM (Hg.). Korner (wie Anm. 138), S. XIX-XXXI; WRIEDT, Bürgerliche Geschichtsschreibung (wie Anm. 143), S. 31; vgl. hingegen: HRUSCHKA, Kriegsführung (wie Anm. 12), S. 34.

${ }^{146}$ HruschKa, Kriegsführung (wie Anm. 12), S. 168 mit Anm. 524; vgl. MöHring-MüLLER, Helga, Die „Chronica Novella“ des Lübecker Dominikanermönchs Hermann Korner. Untersuchungen zu Gattung, Sprache, Publikum und Inhalt der lateinischen und mittelnie- 
novella" einen Stortebeker: zum Frieden zwischen Albrecht und Margarethe 1395 und zum Kampf gegen die Hamburger, bei Korner im Jahr 1402. Zu 1395 sind in den ersten Fassungen Ká, KA und KB (1416, 1420, 1423) noch keine Angaben enthalten. Erst in KD von 1435 gibt Korner an, dass ein Teil der Vitalienbrüder sich nach Friesland zurückgezogen habe: Quorum capitanei fuerunt Wigboldus, Godfridus Michaelis et Stortebeker ac ceteri. ${ }^{147}$ Die mittelniederdeutsche Fassung KH von 1438 verweist bereits auf das (angebliche) weitere Geschehen: [...] unde sochten dar na wedder de Elve unde worden to deme lesten ghegrepen van den van Hammeborg unde worden dar gekoppet. Desser hovetlude weren genomet Wigbolt, Godeke Micheles unde Stortebeker. ${ }^{148}$ Denn zum Jahr 1402 schildert Korner mit zunehmender Ausführlichkeit den Kampf der Hamburger cum pyratis qui in mari remanserunt ex maledicta colleccione raptorum, quam civitates Rostok et wismer fecerant pro liberacione alberti eorum ducis, licet protunc essent per eos licenciati. Schon Korner also versucht, den Unterschied zwischen legitimer Fehdehilfe bzw. Kaperfahrt und illegitimer Seeräuberei zu erklären, und wertet den Fortbestand der Vitalienbrüder nach 1395 als Verstoß gegen das Fehderecht.

Zunächst jedenfalls seien Wichmannus et Stortebeker mit ihren Leuten den Englandfahrern ins Netz gegangen, dann Gotfridus Michaelis et Wigboldus magister in artibus. ${ }^{149}$ In der letzten lateinischen Fassung (KD, 1435) hat unser Kandidat einen Vornamen: Nicolaus Stortebeker. ${ }^{150}$ Der unbekannte Verfasser der Rufus-Chronik stützte sich für seine Berichte über diese Ereignisse auf die verlorene Fassung KC Korners. ${ }^{151}$ Da er unseren Kaperfahrer Clawes Stortebeker nennt, muss Korner diesen Vornamen schon in KC, also etwa 1430, eingeführt haben. ${ }^{152}$

derdeutschen Fassungen, in SPRANDEL, Rolf (Hg.): Zweisprachige Geschichtsschreibung im spätmittelalterlichen Deutschland (Wissensliteratur im Mittelalter, Bd. 14), Wiesbaden 1993. S. 27-121, hier: S. $116 f$.

${ }^{147}$ Schwalm (Hg.), Korner (wie Anm. 138), S. 345; vgl. Koppmann (Hg.), Rufus (wie Anm. 101), S. 2, Anm. 6.

${ }^{148}$ Koppmann (Hg.), Rufus (wie Anm. 101), S. 2, Anm. 6; vgl HruschKa, Kriegsführung (wie Anm. 12), S. 364f. (aus der Wiener Handschrift KW): De ouerst van dossen Vitalien Broderen jn de Westerse gheseghelt weren, de quemen in Hispanien vnde schinden dar den kopman vnde sochten dann wedder de Elue vnde worden to deme lesten ghegrepen van den van Hamborch vnde worden dar ghekoppet. Dosser houethude weren ghenonuet Wigolt, Godeke IMechnels gestr. I Micheles unde Stortebeker.

${ }^{149}$ SChwal.m (Hg.), Korner (wie Anm. 138), S. 98. S. 363f.

${ }^{150}$ Ebenda; KoppmanN (Hg.), Rufus (wie Anm. 101), S. 25, Anm. 7; vgl. HruschKa, Kriegsführung (wie Anm. 12), S. 368 (aus der Wiener Handschrift KW): Clawes Stortebeker. Im Bericht zum Jahr 1395 behält Korner die Benennung allein mit dem Nachnamen bei vielleicht ein Indiz für eine eher akzidentielle Ergänzung?

${ }^{151}$ KoppMann (Hg.), Rufus (wie Anm. 101), Einleitung, S. XIf., S. XVIIf.

${ }^{152}$ Koppmann (Hg.), Rufus (wie Anm. 101), S. 2, S. 25f.; vgl. KoppmanN, Einleitung ebenda, S. XIf., S. XVIII. 
Im Kern wird man Korners Informationen nicht als reine Phantasie abtun können, zumal sie ja durch die archivalische Überlieferung gestützt werden: Johann Stortebeker und einige andere Kaperkapitäne ${ }^{153}$ waren demnach nach 1395 in der Nordsee aktiv; vielleicht kämpften sie auftragsgemäß gegen die Hamburger; ob sie freilich die Verlierer der Schlacht vor Helgoland waren, bleibt unklar.

Den Vornamen Nicolaus bzw. Clawes jedoch fügte Korner erst ca. 30 Jahre nach den Geschehnissen in den Bericht ein. Zu dieser Zeit waren mit Hermann und Marquard Stortebeker zwei „Auslieger“ ähnlichen Namens im Hanseraum aktiv. ${ }^{154}$ Der Danziger Johann Stortebeker war vielleicht nicht mehr am Leben. Wie gut Hermann Korner in Erfurt oder bereits wieder in Lübeck über die Kleinkriege seiner Zeit informiert war, bleibt unklar. Jedenfalls hatte er Grund, seine Angaben zu präzisieren, und der hansestädtische Allerweltsname „Nikolaus“ legt den Verdacht nahe, dass er sich dabei nicht mit skrupulöser Quellenkritik aufhielt.

Wie steht es aber um die Hinrichtung der Gefangenen? Nach der Erwähnung der Schiffsführer heißt es da (KB): Et hammeburgenses ex eis interfecerunt CCXL prope insulam Terre Sancte, $L X X$ vero secum duxerunt in suam urbem et ibidem decollati sunt [...]. ${ }^{155}$ Die Formulierung ex eis kann nun die genannten Kapitäne einschließen, sie muss dies aber nicht. Klarer ist die Sache hingegen für Gödeke Michels und seine Leute formuliert, dessen Tod ja auch in den Hamburger Kämmereirechnungen überliefert ist: Hii omnes ut primi in urbem Hammeburg sunt ducti pariter et decapitati. ${ }^{156}$ Zufall oder ganz bewusste Stilisierung - eine genaue Lesart des Berichts Korners bietet zumindest keinen sicheren Beleg für eine Hinrichtung des Stortebeker. Und auch die Rufus-Chronik, geschrieben zwischen 1430 und 1438 ebenfalls in Lübeck, spricht nicht ausdrücklich für den Tod Störtebekers: Se slughen erer beh den 40 doet by Hilghelande unde vinghen erer by 70. de brachten se myt syk to Hamborch, unde leten en allen de hovede afslan; [...] desser vitalien hovetlude weren ghenomet Wichman und Clawes Stortebeker. ${ }^{157}$

${ }^{153}$ Zumindest die Namen Gödeke Michels und Störtebeker tauchen auch in den Klageakten auf, vgl. KoppManN, Seeräuber (wie Anm. 4). S. 39.

${ }^{154}$ Vgl. oben, Kap. 5.

${ }^{155} \mathrm{Vgl}$. HRUSCHKA, Kriegsführung (wie Anm. 12), S. 368 (aus der Wiener Handschrift KW): Dar sloghen de Hamborgher dot der Likendelere by verthigen vnde vinghen erer by souentighen.

${ }^{156}$ In der deutschen Fassung weniger klar. vgl. HRUSCHKA, Kriegsführung (wie Anm. 12), S. 368 (aus der Wiener Handschrift KW): Do grepen de van Hamborch by achtentich see rouers vide brochten se mede tho hamborch vinde setten ere houede by de anderen vppe dat werder buten deme schare.

${ }^{157}$ KoppmanN (Hg.), Rufus (wie Anm. 101), S. 25 f. 
Ausdrücklich von einer Hinrichtung Störtebekers hingegen sprechen mehrere Hamburger Chroniken, die zum Umfeld der sogenannten „Wendischen Städtechronik“ gehören. Die ältesten Teile dieses Werks datiert der Herausgeber Johann Martin Lappenberg schon in das erste Viertel des 15. Jahrhunderts. In mehreren Redaktionen sei sie zunächst bis 1470, dann bis 1530 bzw. 1534 geführt worden. Alle überlieferten Handschriften stammen aus dem 16. Jahrhundert. ${ }^{158}$ Daher hat Heinrich Reincke die „Wendische Chronik“ insgesamt erst als Produkt des 16. Jahrhunderts sehen wollen. ${ }^{159}$ Solange eine moderne Edition mit präziser Differenzierung der Redaktionen nicht vorliegt, wird man also zum Entstehungshorizont einzelner Abschnitte, und ebenso zu möglichen Abhängigkeiten von Korner und „Rufus“, keine abschließenden Aussagen treffen können.

Die von Lappenberg kollationierte Edition jedenfalls erwähnt zu 1402: Item dessuluen iars 2 do grepen de van Hamborch im ersten de ßerouers, alße. Wichman vnde Storteheker, dede worden gerichtet tohant na Feliciani. ${ }^{160}$ Den Kampf gegen Wichbolt und Gödeke Michels verlegt sie ins Jahr 1403. Eine der Quellen der Wendischen Chronik, die sogenannten „Hamburgischen Jahrbücher" (von 1457) wiederholt diese Angaben:

Anno xiiii ${ }^{c}$ twe ward Wichman vnde Stortebeker afghehouwen altohand na Feliciani; --lv.

Anno xiiii dre iar ward Wikbolt vnde Godeke Michael afghehouwen; --liiij. ${ }^{161}$.

Eine stark abweichende Variante der „Wendischen Städtechronik“ (bei Lappenberg HS 4: Hannover) hingegen gibt für beide Schlachten das gleiche Jahr, und sie erwähnt den schon bekannten Vornamen unseres Protagonisten: Anno Domini 1402 do haleden de Hamborger tor ersten tit Wichman vnd Claus Stortebeker. Dar bleuen in der see 40 man vnd 70 wurden vor Hamborch enthouedet. Vnd im suluen iare wurt gekoppet Gotke Michel vnd Wichbolt bei 80 personen. ${ }^{162}$ Die Abweichungen im Text, neben der Datierung insbesondere die Zahlenangaben zu den Opfern, erinnern nun wohl nicht von ungefähr an die Rufus-Chronik. Man wird also auch den Namen Claus als Übernahme aus der Lübecker Überlieferung ansehen können. Und im Gegensatz zur Hauptüberlieferung der „Wendi-

\footnotetext{
158 Johann Martin LAPPENBERG (Hg.), Hamburgische Chroniken in niedersächsischer Sprache, 1861, S. $229 \mathrm{f}$.

${ }^{159}$ Heinrich REINCKE, Untersuchungen über Hamburgs mittelalterliche Geschichtsschreibung, in: ZVHG 24 (1931), S. 1-31. hier S. $11 \mathrm{f}$.

${ }^{160}$ LAPPENBERG (Hg.), Hamburgische Chroniken (wie Anm. 158), S. 240 f.

${ }^{161}$ LAPPENBERG (Hg.), Hamburgische Chroniken (wie Anm. 158), S. 227; vgl. ebd., S. XXIII; Lappenberg sah in den „Jahrbüchern“ einen Auszug aus der „Wendischen Chronik“; REINCKE, Untersuchungen (wie Anm. 159), S. $11 \mathrm{f}$., hingegen identifiziert sie als Vorlage.

${ }^{162}$ LAPPENBERG (Hg.), Hamburgische Chroniken (wie Anm. 158), S. 240 f.
} 
schen Chronik" spricht auch diese Handschrift nicht ausdrücklich von einer Hinrichtung der Schiffsführer aus dem ersten Gefecht.

Einen quellenmäßigen Beleg für die Hinrichtung Störtebekers in Hamburg bietet also auch die „Wendische Chronik“ nicht. In jedem Fall stehen gegen die unsichere chronikalische Überlieferung die sehr konkreten archivalischen Belege für den lebenden Störtebeker nach 1400/01.

Doch abseits philologischer Details wurde in der zweiten Hälfte des 15. Jahrhunderts die von Hermann Korner und der „Rufus"-Chronik vorgeprägte Sicht der Helgoländer und Hamburger Ereignisse zum Allgemeingut. Die 1486 in Lübeck gedruckte „Chronica Slavica“ erwähnt den fraglichen Vornamen nicht, wohl aber das Ereignis: Anno D[omini] 1402 Hamborgenses decapitaverunt plures piratas, scil[icet] Wigboldum, Godfridum Michaelem, Stortebeker cum suis complicibus. ${ }^{163}$ Schon mit diesem Druck könnte die Erzählung über den heldenhaften Sieg der Hamburger weitere Verbreitung auch außerhalb der Rezipientenkreise handschriftlicher Chroniken gefunden haben.

Ungleich größere Wirkung jedoch hatte Albert Krantz (1448-1517), Syndikus des Lübecker und Hamburger Rats, Lektor an der Domschule und Dekan des Hamburger Domkapitels, mit seiner „Wandalia“. ${ }^{164} \mathrm{Er}$ schildert in epischer Breite, wie die Hamburger kämpften, biß vber die Viertzig von den Freybeutern vmb kahmen, vnd in die Siebentzig gefangen wurden, deren Capitain waren Wichman unnd Claus Stoertebeker, die brachte man saemptlich gehn Hamburg, aldar sie mit dem schwertde ihren verdienten lohn empfingen. ${ }^{165}$ In seinem Bericht flossen nun offensichtlich die Kornersche Tradition, eventuell Informationen aus städtischen Archivalien und orale Überlieferungen, die sich in der Zwischenzeit angelagert hatten, zusammen. ${ }^{166}$ Und Albert Krantz gab auch den lokalpatriotischen Ton vor, der in Zukunft die hamburgische Wahrnehmung der sich entwickelnden Legende bestimmen sollte: Vnter andern lob vnd ruehmblichen thaten der Stadt Hamburg ist diese der fuernemsten eine, das sie weidlich den seehanen auff die federn zu greiffen, vnd dieselben auffs haertest vnd schaerffeste verfolgen. Denn sie wissen auch wol, wenn der Schiffmann keinen freyen paß zur See hat, das ihnen ihr gewinn allßdan auch abgehet.

Mit Krantz' „Wandalia“, einem in deutscher und lateinischer Sprache vielfach aufgelegten Bestseller der Geschichtsschreibung, hatte der

\footnotetext{
${ }^{163}$ Zitiert nach: LAURENT, Störtebeker (wie Anm. 55), S. 74.

${ }^{16+} \mathrm{Vgl}$. allg. zuletzt: Ulrich ANDERMANN, Albert Krantz. Wissenschaft und Historiographie um 1500 (Forschungen zur mittelalterlichen Geschichte, Bd. 38), Weimar 1999.

${ }^{165}$ KrantZ, Wandalia (wie Anm. 13), Buch X, Cap. 6, S. 344f.

${ }^{166}$ KOPPMANN, Seeräuber (wie Anm. 4), S. 49.
} 
Mythos sein Medium gefunden. Die Vitalienbrüder waren in der Legende längst zu reinen Seeräubern mutiert, während in der Wirklichkeit der Kriegsführung aus den bezahlten Fehdehelfern des späten Mittelalters die Söldnerkompanien des 16. und 17. Jahrhunderts geworden waren. Störtebeker und Güdeke Michels galten nun als die mächtigsten Anführer der berüchtigsten Seeräuber, und wo immer historische Fakten, landschaftliche Gegebenheiten, gesellschaftliche Bedürnisse oder schlicht die Phantasie dies zuließen, wurden sie in die schriftliche und mündliche Überlieferung integriert.

Ein prominentes Beispiel: Im ostfriesischen Marienhafe etwa erinnerte man sich zu Recht an die Anwesenheit von Vitalienbrüdern zur Zeit Widzel und Keno tom Brokes. ${ }^{167}$ Eggerik Beninga (1490-1562) jedoch hatte sicher Krantz' „Wandalia“ vor Augen, vielleicht auch schon eine lokale Legende im Ohr, als er der Kirche von Marienhafe ihren Gründungsmythos verschaffte:

Darna im sulven jaere is de toren to Marienhove in Broeckmerlandt vordan in den hoege upgetimmert, to welcker karcke, toeren und poerten mit der muren Stortebeker und Goedeke Michaell itliche dusende vorhen (dat welcke se in der zee mit roeven erovert) gegeven, overmitz, dat se ore scepe an de muren mit ketten bevestigen kunden. Dusse beiden synnen to Hamborch (wo hir vorgeroert) gefencklich angenamen und na ore vordenste oe loen untfangen. ${ }^{168}$

Beningas Chronik wurde zur Vorlage für Ubbo Emmius und seine Rerum Frisicarum Historiae (1616), ${ }^{169}$ und wohl auch für Bernhard Elsenius' Chronicon Rerum Frisicarum Orientalis (bis 1631). ${ }^{170}$ So entwickelte sich eine Tradition, die noch heute die Störtebeker-Legende prägt - und den ostfriesischen Fremdenverkehr ebenso.

Außerhalb Ostfrieslands jedoch wurde eine andere Tradition maßgeblich: Um 1550 erschienen erstmals Flugblätter mit dem berühmten Störtebeker-Lied, ausgerechnet in Nürnberg, bzw. Regensburg und in frühneuhochdeutscher Sprache. Es handelt sich dabei wohl um die Überset-

\footnotetext{
${ }^{16 i}$ Mit vielen suggestiven Mutmaßungen: WoEBCKEN, Störtebeker (wie Anm. 117), S. 136-140.

${ }^{16 x}$ Eggerik BeningA, Cronica der Fresen. Bearb. von Louis HAHN. Aus d. Nachlaß hg. von Heinz RAMM (Quellen zur Geschichte Ostfrieslands), Aurich 1961 Bd. 1, S. 345 (zu 1459); zu 1396-1402 enthält die Chronik keine Angaben über Störtebeker oder Michels. Zur Person vgl. ebenda, S. 1-10. zur Entstehung und Überlieferung der Chronik, S. 72-79, S. 93f.; zu Albert Krantz als Vorlage für die Behandlung der Vitalienbrüder, S. 100.

${ }^{169}$ Beninga, Cronica (wie Anm. 168), S. 67f.; WoEbCKEn, Störtebeker (wie Anm. 117), S. $144 \mathrm{f}$.

${ }^{170}$ BENTS, Dichtung (wie Anm. 2), hier: ${ }^{2} 2003$, S. 70, nennt diesen als Quelle für die Anwesenheit Störtebekers in Marienhafe.
} 
zung eines niederdeutschen Originals. ${ }^{171}$ Dieses ist jedoch nicht überliefert, erst im 19. Jahrhundert kamen niederdeutsche Fassungen zum Druck. Stattdessen gewann das hochdeutsche Störtebeker-Lied in der zweiten Hälfte des 16. Jahrhunderts eine breite Wirkung, fand Aufnahme etwa im „Ambraser Liederbuch", wurde zitiert in Johannes Fischarts "Gargantua" für andere Lieder als „Ton“ zur Melodievorlage genommen. In manchem, etwa der Erwähnung des Schiffes „Bunte Kuh“, erinnert das Lied an Albert Krantz, ebenso in der Heroisierung der Hamburger und der moralisierenden Verurteilung der "Seeräuber".

Aus anderen Quellen schöpft der Dichter jedoch mit der Einführung eines Gegenspielers für Störtebeker und Gödeke Michels: Simon von Utrecht. Er war 1399 aus Harlem als „Auslieger“ in die Hansestadt gekommen, und sollte später bis zum Bürgermeister aufsteigen. An den Kämpfen gegen die Fehdehelfer des Grafen von Holland 1400/01 war er tatsächlich beteiligt, freilich nur als Kommandant einer Schnigge, eines Schnellbootes also. In den Zwanziger und Dreißiger Jahren jedoch hatte er sich als Oberkommandierender bei diversen Kriegszügen um die Stadt verdient gemacht. ${ }^{172}$ Vor allem jedoch hatte er testamentarisch seiner Stadt Renten überschrieben für den Unterhalt von „Barsen“, Patrouillenbooten für die Kontrolle der Unterelbe. So konnte er in der Traditionsbildung der Hansestadt zum Retter des Vaterlandes werden. Als 1566 sein Grab in der Nikolaikirche zum Wiederverkauf anstand, konnte der Rat die Kirchgeschworenen davon überzeugen, wenigstens ein neues Epitaph an Stelle des verwitterten alten aufzustellen. Im Jahr 1661 schließlich bekam unser Held wiederum ein neues Denkmal, mit einer Inschrift, die seine legendären Verdienste prägnant zusammenfasst:

ANNO DOMINI 1437 IN DIE CALIXTI OBIIT VENERABILIS VIR DOMINVS SIMON DE VTRECHT HVIVS CIVITATIS IP]ROCONSVL / IPJIRATAS STORTBECK QVI CEIPIIT GÖTKE MICHAEL / HIC SITAE

\footnotetext{
${ }^{171}$ Hartmut BECKERS, (Art.) Störtebeker, in: Die deutsche Literatur des Mittelalters. Verfasserlexikon. 2. Auflage, Bd. 9 (1995). Sp. 364-366; PUHLE, Vitalienbrüder (wie Anm. 4), S. 161 f.; Posrel, Pirat (wie Anm. 20), S. 63f.; LAurent, Störtebeker (wie Anm. 55), S. 99f., S. 595-598 (LAPPEnberG); WALTHER. Namen (wie Anm. 111), S. 90; KoppmanN, Seeräuber (wie Anm. 4), S. 49f., WOEBCKEN, Störtebeker (wie Anm. 117), S. $150 \mathrm{ff}$; Dieter MöHN, Störtebeker und die Folgen. Von der Faszination eines Stoffes in der deutschen Literaturgeschichte, in: Niederdeutsches Jahrbuch 118 (1995), S. 99-120, hier: S. 107f.

172 Heinrich REINCKE, Simon von Utrecht. Eine Lebensskizze, in: Forschungen und Skizzen zur hamburgischen Geschichte, hg. von Heinrich REINCKE (Veröffentlichungen aus dem Staatsarchiv der Hansestadt Hamburg), Hamburg 1951, S. 221-240; BRACKER. Nur einer von ihnen (wie Anm. 5), S. 33. 40-42; POSTEl, Pirat (wie Anm. 20), S. 63; Bracker, Seeraub (wie Anm. 12), S. 26-28; NiRRnheim, Hamburg und Ostfriesland (wie Anm. 4), S. 76; KAMMLER. Andreas, Die Hamburger Expedition von 1433 nach Emden und gegen die Sibetsburg vor dem Hintergrund der Ausstattungsliste, in: DSA 25 (2002), S. 223-237, hier: S. 225.
} 
SIMONIS OSIIS AVIDES / DISCAT [P]OSTERITAS MAIORVM FORTIA FACTA SECTARI [P]ATRAE NE CADAT VRBIS HONOS. ${ }^{173}$

Mitte des 17. Jahrhunderts waren es die Korsaren aus den sogenannten Barbareskenstaaten Nordafrikas, die auch die hamburgische Schifffahrt bedrohten. 1662 sollten zwei neue Konvoischiffe, schwer bewaffnet zum Schutz der Handelsflotten, in Dienst gehen. Für Bau und Ausrüstung brauchte die Stadt das Geld ihrer Bürger, so wird es kein Zufall sein, wenn man im Jahr zuvor dem sagenhaften Helden der Vorzeit und edlen Stifter ein neues Denkmal setzte. ${ }^{174}$

Denn längst war Störtebeker im deutschen Sprachraum als größter Pirat der Geschichte bekannt. Bekam er andernorts häufiger Züge eines ,guten Räubers“, eines „Sozialrebellen“ zugeschrieben, so wurde er in Hamburg zum Inbegriff eines Staatsfeindes. ${ }^{175}$

Zum dreihundertjährigen Jubiläum der legendären Hinrichtung sollte Klaus Störtebeker dann endgültig zum exemplarischen Bösewicht der Hamburger Geschichte werden: Seit 1696 tauchten französische Kaperfahrer unter dem Befehl Jean Baerts, die in Nordsee und Kanal eine Handelssperre gegen die Niederlande durchzusetzen trachteten, wiederholt vor der Einfahrt in die Unterelbe auf. Erneut diente der Kampf gegen Störtebeker nun als historisches Vorbild: Zwei Medaillen mit spöttischen Porträts des großen Seeräubers wurden 1700 und 1701 geprägt - eine auf der Rückseite mit einem Bildnis Jean Baerts. Spätestens damit wurde das auch heute noch bekannte angebliche Störtebeker-Porträt kanonisch. ${ }^{176}$ Ein Flugblatt erinnerte im selben Jahr an das Seegefecht vor Helgoland und die angebliche Hinrichtung in Hamburg. ${ }^{177}$ Und Reinhard Kaiser, einer der Begründer der deutschen Barockoper, komponierte die Oper Störtebeker und Jödge Michael. ${ }^{178}$

${ }^{173}$ Heute im Museum für Hamburgische Geschichte. „B“ zu „P“" emendiert; die Transkription folgt: REINCKE, Simon von Utrecht (wie Anm. 172), S. 239; vgl. BRACKER. Seeraub (wie Anm. 12), S. 26-28; Ders., Nur einer von ihnen (wie Anm. 5), S. 39f.: DERS. (Hg.), Die Hanse (wie Anm. 5), Nr. 24.57, Bd. 2, S. $617 \mathrm{f}$.

${ }^{174}$ BRACKER, Ruhm (wie Anm. 13), S. 66lf.

${ }^{175}$ Matthias PuhLE, Hinrichtung ohne Prozeß? Die Hanse um 1400 im Kampf gegen die Seeräuber Klaus Störtebeker und Godeke Michels, in: Große Prozesse. Recht und Gerechtigkeit in der Geschichte, hg. von Uwe SchultZ, München 1996, S. 77-88, hier: S. 87; grundlegend: KOPPMANN. Seeräuber (wie Anm. 4), S. 51-58: WOEBCKEN, Störtebeker (wie Anm. 117), S. 144-150; MÖHN, Folgen (wie Anm. 171), besonders S. 111 f.

${ }^{176} \mathrm{Vgl}$. Gregor RohmanN, Vier Männer und ein Bild. Was verbindet Kunz von der Rosen, Gonsalvo di Cordova, Klaus Störtebeker und Florian Geyer? Über das sogenannte Störtebeker-Porträt, in: BraCKER (Hg.), Gottes Freund (wie Anm. 5), S. 36-51.

177 Abb.: PuHLE, Vitalienbrüder (wie Anm. 4), S. 164.

${ }^{178}$ Laurent, Störtebeker (wie Anm. 55), S. 598; Möhn, Folgen (wie Anm. 171), S. 116-118. 
Die Legende war längst historisch wirksam geworden, insofern viel „wirklicher“ als die historischen Fakten. Bis heute, ja: in den letzten Jahrzehnten multimedial ungleich verstärkt, treibt sie immer neue Blüten. Die Geschichte Johannes Stortebekers aus Danzig nimmt sich ihr gegenüber eher unscheinbar aus. Ihr fehlt auch sicher das vielfältigc Identifikationspotential der Legende. Für eine Erforschung der Geschichte der Vitalienbrüder jedoch ist sie augenscheinlich ungleich fruchtbarer.

\section{Fazit}

Die quellenmäßig nachweisbaren Angaben über einen Beteiligten an den Seekriegen der Zeit um 1400 mit dem Namen „Störtebeker“ (und Varianten) lassen sich am ehesten dem Danziger Schiffer Johann/Johannes Stortebeker zuweisen. Er ist von 1394 bis 1413 als Schiffsführer im Kapergeschäft, aber auch im zivilen Handel nachweisbar. Die Namensangabe „Klaus Störtebeker“ ist hingegen eine arbiträre Zugabe der Chronistik. Ebenso erst Produkt der späteren Geschichtsschreibung ist die Behauptung, „Störtebeker" sei im Jahr 1400 bzw. 1401 in Hamburg hingerichtet worden. Dies gilt umso mehr für alle weiteren Zutaten dieses beinahe unüberschaubaren narrativen Komplexes.

Die Geschichte Johann Stortebekers, soweit sie sich uns anhand der Quellen erschließt, wird nur verständlich vor dem Hintergrund einer grundsätzlichen Revision unserer Sicht auf Fehderecht und Kriegsführung an der Wende zum 15. Jahrhundert. Professionelle Kämpfer und ihre Führungspersonen konnten im Auftrag ihrer eigenen Stadt bzw. Herrschaft Krieg führen. Sie konnten sich auf privatwirtschaftlicher Basis an den Kämpfen ihrer Obrigkeit beteiligen, oder auch in kommerziellem Interesse für fremde Herren kämpfen. In den vielfältigen Konfliktlinien im gesamten Nord- und Ostseeraum boten sich hierfür so zahlreiche Möglichkeiten, dass in der Rückschau kaum festzustellen ist, wann welche Auseinandersetzung bestimmend war. Ebenso konnten Kaperfahrer in Friedenszeiten aber auch Arrestierungen in privatrechtlichen Vollstreckungsverfahren durchführen. Schließlich verfolgten sie vielfach ihre eigenen Interessen und Händel. Es gab folglich beinahe immer einen legitimen oder zumindest legitimierbaren Grund zur Ausübung von Gewalt oder Entwendung von Gütern.

Im immer noch graduell rechtsfreien Raum der See trafen sich dabei Kämpfer unterschiedlicher Herkunft und sozialer Stellung: städtische Würdenträger als Kommandanten von Kriegsschiffen, Handelsschiffer als Teilzeit-Kaperfahrer in eigener oder fremder Sache, professionelle Kriegsunternehmer, dazu ein großes Reservoir an armen, ungebundenen 
Mannschaften. Bei ihren Operationen kam es offenbar immer wieder zu den verschiedensten kurzfristigen Verbindungen. Dieses Geschäft zwischen Handel, Fehdehilfe und Kriegsführung war grundsätzlich alles andere als ehrenrührig. Eine gesellschaftliche Marginalisierung drohte aber alle jenen, die ohne langfristige Loyalitätsbindungen allein auf die erwerbsmäßige Gewaltausübung angewiesen waren.

Denn in den Jahrzehnten zwischen den Kriegen der Hanse gegen Waldemar Atterdag und den Auseinandersetzungen der Zwanziger und DreiBiger Jahre des 15. Jahrhunderts kam es im nordeuropäischen Raum zu einem grundsätzlichen Wandel der seekriegsrechtlichen Rahmenbedingungen. Aus dem durch das Fehderecht gedeckten Schadentrachten gegen den Feind und seine Helfer entstanden die Grundzüge der zumindest gewohnheitsrechtlich regulierten Prisennahme im Unterschied zur damit kriminalisierten Piraterie. Die Bezeichnung „Vitalienbrüder" in den hansischen Quellen verweist, so scheint es, auf jene Gruppen unter den Gewaltprofessionellen ihrer Zeit, die im Zuge dieses Umwertungsprozesses in die Gefahr gerieten, ihre Ehre und ihre soziale Stellung zu verlieren.

Der Danziger Johannes Stortebeker war offenbar zumindest zeitweise eng mit diesen „Vitalienbrüdern“" verbunden. Während einige seiner Kooperationspartner jedoch nach militärischen Niederlagen tatsächlich auch sozial ausgegrenzt wurden und den Tod fanden, konnte er offenbar auf intakte Beziehungen in seiner Stadt und ihrem Umfeld bauen. $\mathrm{Zu}$ keinem für uns ersichtlichen Zeitpunkt war er ein „Outlaw“. Eher schon dürfte er für die Bemannung seines Schiffes auf das große Rekrutierungsreservoir der "losen parthey" zurückgegriffen haben. Vielleicht war er also eher ein Kriegsunternehmer, der „Vitalienbrüder“ anstellte, als dass er selbst als solcher $\mathrm{zu}$ sehen ist. Zum Oberkommandierenden einer angeblichen Piratenarmee, zur Inkarnation eines Seeräubers machte ihn erst die Legende, deren Dynamik auch und besonders von jenem rechtlichen Wandlungsprozess lebt, der sich anhand seines Lebens beschreiben lässt.

Diese Umwertung von der spätmittelalterlichen Fehdepraxis zum frühmodernen Kaperrecht ist in ihrer frühen Phase nach wie vor kaum erforscht. Eine Untersuchung von Fehde- und Seekriegsführung im Hanseraum um 1400 könnte in drei komplementären Schritten erfolgen: 1. Ein unbedingtes Desiderat ist die schon von Benninghoven angemahnte Prosopographie zu Kaperfahrt bzw. Fehdehilfe bzw. Seeraub im Einzugsgebiet der Hanse, etwa für die Zeit von 1370 bis 1435, zunächst wohl anhand der edierten Quellen. 2. Ebenso könnte bei den Hanserezessen und Urkundenbüchern eine begriffsgeschichtliche bzw. historisch-semantische Untersuchung zum Wandel der Terminologie und Konzeptionen von Fehde, Krieg, (See-) Raub etc. ansetzen. 3. Anknüpfend an die Forschungen 
Böhringers und Kammlers zum späteren 15. Jahrhundert wäre rechtshistorisch eine genauere Erforschung der seerechtlichen und politischadministrativen Praxis der beteiligten Mächte, insbesondere natürlich der Hansestädte seit der Mitte des 14. Jahrhunderts, notwendig. Eine weitere Forschung anhand dieser Leitlinien könnte das hier nur umrisshaft aufscheinende Bild von der Geschichte der „Vitalienbrüder" und ihrer Zeit aufklären. Sie könnte den irritierenden Befund zur Person „Störtebeker" verständlicher machen. Und sie könnte die Geschichtswissenschaft aus den Verstrickungen der Mythologie befreien. 